\title{
FACTORS AFFECTING THE SIMULATED TRAJECTORY AND INTENSIFICATION OF TROPICAL CYCLONE YASI
} (2011)

\author{
CHELSEA L. PARKER ${ }^{* 1,2}$, AMANDA H. LYNCH ${ }^{1,2}$, AND PRISCILLA A. \\ MOONEY $^{3}$
}

${ }^{1}$ Department of Earth, Environmental and Planetary Sciences, Brown University, Providence, RI, USA

${ }^{2}$ Institute at Brown for Environment and Society, Brown University, Providence, RI, USA

${ }^{3}$ National Center for Atmospheric Research, Boulder, CO, USA

*Corresponding Author

Contact: chelsea_parker@brown.edu (+1) 401-863-5452

85 Waterman St, P.O. Box 1951

Building for Environmental Research and Teaching \#145

Providence, RI, 02912

USA.

This revised manuscript was submitted to Atmospheric Research $3^{\text {rd }}$ March 2017 


\section{Abstract}

This study investigates the sensitivity of the simulated trajectory, intensification, and forward speed of Tropical Cyclone Yasi to initial conditions, physical parameterizations, and sea surface temperatures. Yasi was a category 5 storm that made landfall in Queensland, Australia in February 2011. A series of simulations were performed using WRF-ARW v3.4.1 driven by ERA-Interim data at the lateral boundaries. To assess these simulations, a new simple skill score is devised to summarize the deviation from observed conditions at landfall. The results demonstrate the sensitivity to initial condition resolution and the need for a new initialization dataset. Ensemble testing of physics parameterizations revealed strong sensitivity to cumulus schemes, with a trade-off between trajectory and intensity accuracy. The Tiedtke scheme produces an accurate trajectory evolution and landfall location. The Kain Fritch scheme is associated with larger errors in trajectory due to a less active shallow convection over the ocean, leading to warmer temperatures at the $700 \mathrm{mb}$ level and a stronger, more poleward steering flow. However, the Kain Fritsch scheme produces more accurate intensities and translation speeds. Tiedkte-derived intensities were weaker due to suppression of deep convection by active shallow convection. Accurate representation of the sea surface temperature through correcting a newly discovered SST lag in reanalysis data or increasing resolution of SST data can improve the simulation. Higher resolution increases relative vorticity and intensity. However, the sea surface boundary had a more pronounced effect on the simulation with the Tiedtke scheme due to its moisture convergence trigger and active shallow convection over the tropical ocean. 


\section{Keywords}

Australia; Weather Research and Forecasting (WRF) model; tropical cyclone; Yasi; initial conditions; cumulus parameterization; sea surface temperature.

\section{Introduction}

During the last two decades, the northeast coastal regions of Australia have experienced increased total rainfall and more frequent heavy rainfall (Alexander et al. 2007, Lynch et al. 2008). Since 2003, a number of intense TCs have affected the area (Great Barrier Reef Marine Park Authority 2011a; Beeden et al. 2015); in contrast with previous decades (1970-2003), when there were no TCs greater than category 1 on the

Saffir-Simpson scale (category 3 on the Australian scale) recorded in the area (Puotinen et al. 1997, Puotinen 2007). For this region, during this time period, it is perceived that the frequency of total tropical cyclone (TC) events has increased (Great Barrier Reef Marine Park Authority 2011a; Beeden et al. 2005), while the proportion of high intensity storms has also increased (Nicholls et al. 1998; Alexander et al. 2007; Holland and Bruyère 2013). However, analyzing trends in TC intensity and frequency to the present day has been confounded by the availability, quality, and temporal range of historical data (Landsea et al. 2010, Kuleshov et al. 2010, Walsh et al. 2012), particularly in the South Pacific (Walsh et al. 2012; Walsh et al. 2016).

The possible response of TCs to predicted climate change is still an active area of inquiry. The outstanding questions include, the extent to which intensity will will reach the theoretical potential maximum and whether there will be a significant change in genesis location and trajectories (e.g. Walsh et al. 2016). Numerical modeling studies using globalscale General Circulation Models are computationally intensive and may not capture 
environmental conditions favorable for TC genesis and development. The horizontal resolution of these models (from $\sim 100$ to $300 \mathrm{~km}$ for the CMIP5 models down to $\sim 50 \mathrm{~km}$ for the new generation of models [Walsh et al. 2016]) has thus far been inadequate to accurately capture the short-term variability of intense TCs given that high resolution meteorological forcing cannot be supplied by the coarse grid (Walsh 2004, Lynn et al. 2009, Walsh et al. 2016). Regional climate models and climate downscaling techniques are needed to resolve realistic TC intensities, life cycles, and structures such as size and eyewalls (Lynn et al. 2009; Lackmann 2015). The majority of regional studies have focused on the Atlantic basin (Walsh et al. 2012). However, studies have demonstrated that there may be substantial variations in the response of TCs to climate change across basins particularly in terms of frequency and intensity (e.g. Oouchi et al. 2006; Walsh et al. 2006). Previous studies dedicated to the South Pacific and Australia region, have focused on the statistics of overall changes to TCs in the basin (e.g. frequency [Lavender and Walsh 2011], interannual variability of frequency [Walsh 2015], genesis location [Walsh and Katzfey 2000; Nguyen and Walsh 2001], trajectory [Lavender and Walsh 2011], and intensity [Walsh and Ryan 2000]). Accurate representations of TC systems and their characteristics at relatively coarse horizontal grid resolutions (e.g. $12 \mathrm{~km}$ ) in this region are essential for future studies exploring the sensitivity of TCs to climate change forcing. This study acts as a precursor to such studies and assesses the skill and sensitivity of simulating TC-scale characteristics at horizontal resolutions typically used in regional climate studies (12-15km [Jacob et al. 2014]). The findings provide valuable information for initial conditions, physical parametrizations, and surface boundary conditions which can be used for simulating TC-scale characteristics (such trajectory, intensity, and forward speed) in the Australia region. 
TC Yasi was one of the most powerful TCs to affect the Great Barrier Reef and the Queensland coastal region (Great Barrier Reef Marine Park Authority 2011b). Cyclogenesis began just northeast of Fiji on January 29 2011. Yasi tracked westward across roughly $3500 \mathrm{~km}$ of ocean in five days to make landfall at Mission Beach, Queensland, in the early hours of February 3, 2011 (local time) (Figure 1). Within its lifecycle, the system rapidly intensified from a category 3 to a category 5 storm in just 36 hours, covering a distance of roughly $1800 \mathrm{~km}$ (Australian Bureau of Meteorology [BOM] 2011). The destructive winds were estimated to have affected $13 \%$ of the Great Barrier Reef and the economic impacts on tourism, agriculture and coal exports were significant (Queensland Government 2012). Storm intensity was maintained for a considerable distance inland, contributing to further flooding and wind damage over a wide swath of productive agricultural land and World Heritage wilderness regions (AON Benfield 2011). The agricultural losses in Queensland were estimated at AUD\$1 billion (AON Benfield 2011). Total damage and cost to insurers makes Yasi the costliest TC to have affected Australia (Reuters, 2015) due to its anomalously large size, intense wind speeds, and heavy rainfall (particularly inland after landfall). Given Yasi's intensity and destructive capacity, it is important to test the sensitivity and accuracy of this system at a regional model resolution.

The Advanced Research Weather Research and Forecasting model (hereafter, WRF) is a mesoscale numerical weather prediction model. Numerous studies have demonstrated that WRF is suitable for simulating TC events primarily in the Northern Hemisphere (e.g. Davis et al. 2008, Abarca and Corbosiero 2011). Efforts have been made to optimize the model setup, and to demonstrate how parameterizations affect the simulation of TCs. 
Fierro et al. (2009) and Gentry and Lackmann (2010) concluded that increasing horizontal grid spacing (up to $1 \mathrm{~km}$ ) increases accuracy of simulated central pressure and TC processes, particularly in the eyewall. This study assesses the ability of WRF at a coarse horizontal resolution of $12 \mathrm{~km}$ to simulate the intensity and TC lifecycle.

The choice of cumulus parameterization scheme (hereafter CU) influences many aspects of simulation skill including trajectory, landfall time, structure, intensity, precipitation patterns, and accumulation bias (e.g. Wang and Seaman 1997; Gallus 1999; Prater and Evans 2002; Zhang et al. 2011; Nasrollahi et al. 2012; Shepherd and Walsh 2016). Of particular interest to this study, Nasrollahi et al. (2012) found that the BettsMiller-Janjić (BMJ) CU scheme yielded the most accurate TC trajectory; while Prater and Evans (2002) found that BMJ caused TC track recurvature too early, and the Kain Fritsch CU scheme reproduced the most accurate trajectory. However, Torn and Davis (2012) found that the Kain Fritsch scheme produced a large track bias and the Tiedtke scheme produced the trajectory closest to observed. Furthermore, Shepherd and Walsh (2016) discussed that the Kain Fritsh and Tiedtke schemes produced relatively similar trajectories. This study aims to reconcile the sensitivity of the TC Yasi trajectory to the CU parameterization in the chosen WRF set up. Simulated intensity is also highly sensitive to CU scheme, where BMJ (Prater and Evans 2002) and the Tiedtke schemes yield TCs weaker than observed, but the Kain Fritsch scheme has produced more accurate deepening and intensities in the literature (e.g. Torn and Davis 2012; Shepherd and Walsh 2016). This study considers the accuracy of intensity representation to further inform model configuration for TC simulation at this resolution, in this basin. Nasrollahi et al. (2012) found that several combinations of $\mathrm{CU}$ with microphysics schemes were adequate in simulating landfall time. Landfall time may be affected by trajectory and the relative 
location of the coastline, therefore this study considers TC translation speed over the TC lifecycle up to landfall. The sensitivity of translation speed to model set up and parameters has not previously been addressed in depth in the literature. Translation speed is an important TC characteristic to consider as it can affect the ground relative wind speeds (Shapiro 1983), storm surge (Peng et al. 2004; Weisber and Zheng 2006; Rego and Li 2009; Irish and Resio 2010), and the duration of TC-like conditions experienced at any one location.

The microphysics scheme (hereafter MP) can particularly affect simulated intensity (Tao et al. 2011) and precipitation (Nasarollahi et al. 2012). Some studies concluded that modeled trajectory may not be significantly sensitive to MP parameterization (e.g., Yang and Ching, 2005; Zhu and Zhang, 2006; Li and Pu, 2008; Tao et al., 2011). However, others (Fovell and Su 2007; Fovell et al. 2009; Nasrollahi et al. 2012) found that trajectory can be particularly sensitive to the MP parameterization due to the sensitivity of the TC size and outer winds to the MP scheme. Therefore, analyzing the sensitivity of trajectory and intensity to the MP scheme will be included in the physics testing ensemble in this study. Different planetary boundary layer parameterization schemes (hereafter PBL) can alter intensity evolution and structural characteristics (e.g. Braun and Tao 2000; Li and Pu, 2008; Smith and Thomsen 2010; Bao et al. 2012). In particular, the choice of PBL scheme can result in differences of up to $19 \mathrm{hPa}$ in simulated sea level pressure (SLP) in just a $30 \mathrm{~h}$ forecast period ( $\mathrm{Li}$ and $\mathrm{Pu} 2008$ ). Therefore, the effect of the PBL, particularly on the simulated intensity, will be considered in the testing of a physics parameterization ensemble. 
Previous work has explored the sensitivity of TC simulations in WRF to initial condition datasets (e.g. Mohanty et al. 2010) and initial condition time (e.g. Mohanty et al. 2010; Shepherd and Walsh 2016). Shepherd and Walsh (2016) showed that trajectories can be sensitive to initial condition time, however they are more sensitive to the CU parameterization. Mohanty et al. (2010) demonstrated that simulated intensity and vorticity maxima are sensitive to the chosen initial and boundary condition data set. Furthermore, it has been shown that improved initial conditions from data assimilation can particularly improve the representation of intensity ( $\mathrm{Li}$ and $\mathrm{Pu} 2008$; Torn and Davis 2012). Alternatively, nudging could be applied to the model until cyclone genesis, which would constrain the model to be more consistent with observations. However, there are issues concerning the impact of nudging strength on model internal variability (Glisan et al., 2013). Therefore, this study focuses on testing the effect of initial conditions with differing resolutions on the outcome of the TC simulation on this relatively coarse grid.

TC development and intensity are closely related to and controlled by sea surface temperature (SST) (e.g. Schade and Emanuel 1999; Ramsay and Sobel 2011; Bruyère et al. 2012). Therefore, some studies have explored the response of WRF TC simulations to variations in the SSTs boundary conditions. Miglietta et al. (2011) demonstrated that as SST increases, so does the simulated intensity (depth of the minimum pressure) and the persistence of the symmetric warm core. Davis et al. (2008) found that the rate of intensification of Atlantic hurricanes in WRF was particularly sensitive to the SST field and the treatment of mixing feedback and ocean cooling. Mooney et al. (2016) also found that the treatment of the Atlantic SST in the model dictated the accuracy and relative development of the TC-induced cold wake, and therefore the subsequent effect on TC intensity through interaction with the reduced SSTs. This study however, explores whether 
the simulated TC characteristics, such as intensity and trajectory, can be improved on this grid through improvements in the physical representation of the SSTs in the model or through increasing the resolution of the SST boundary condition data.

The results from the literature discussed thus far have been from studies of TC systems in the Northern Hemisphere. Aside from recent work by Shepherd and Walsh (2016), to the best of the authors' knowledge, no other studies have assessed the simulation of TC events in the Western South Pacific region with WRF, and further improvements need to be made for TC simulations in a regional model set up in this region. While forecasts were able to predict the trajectory of TC Yasi accurately, they were unable to capture the intensification, particularly into landfall (Reeder et al. 2012). This study assesses the ability of the WRF model to capture the characteristics of TC Yasi at a relatively coarse horizontal grid resolution, testing the sensitivity of the simulation to (1) initial conditions, (2) physical parameterizations, and (3) sea surface temperature (SST) boundary conditions.

\section{Methods}

\subsection{Model configuration}

The mesoscale numerical weather prediction model WRF-ARW version 3.4.1

(Skamarock et al. 2008) was configured with static two-way nesting for two domains of 36- and 12-km grid spacing (Figure 2). Higher resolutions of horizontal grid spacing may improve the simulation accuracy of intensity in strong TCs, and physical processes such as 
eyewall replacement (e.g. Gentry and Lackmann 2010), and rapid intensification (e.g. Davis et al. 2008). However, studies have shown that a $12 \mathrm{~km}$ grid spacing is sufficient for reproducing sub-system-scale structures such as eye-wall asymmetries and spiral bands (Done et al. 2013). Therefore, we have used the $12 \mathrm{~km}$ spacing in order to carry out a large number of exploratory simulations to address the sensitivity of TC representation in regional climate models, which typically have grid spacings of 10-15 km (Jacob et al. 2014). Both domains are centered on latitude $16.018^{\circ} \mathrm{S}$ and longitude $156.382^{\circ} \mathrm{E}$. All simulations have 28 vertical levels and the model top pressure level was set to $50 \mathrm{hPa}$. The impacts of increased vertical resolution and pressure level distribution were investigated in a similar method as employed by Ma et al. (2012). These factors did not significantly affect the simulation skill as to warrant increased vertical resolution for the remainder of the simulations (see Table 2 Run numbers 9, 10, 11, 12).

All simulations spanned 96 hours to capture the main intensification period and landfall of TC Yasi. Initialization was at 00:00 UTC January 312011 and runs lasted until 00:00 UTC February 4 2011. Lateral boundary conditions were provided by the pressure level data products from the European Centre for Medium-Range Weather Forecasts (ECMWF) Re-Analysis Interim (hereafter ERA-I) data set (Dee et al. 2011). The data are at 6-hourly intervals, $0.7^{\circ}$ spatial resolution, and have 37 atmospheric levels. Surface data at 6-hourly intervals were also used.

\subsection{Initial Conditions}

While others have tested simulation sensitivity to initial condition time (e.g. Shepherd and Walsh 2016), this study tested sensitivity to initial condition spatial 
resolution. We compared two initialization techniques: (1) the ERA-I data as both boundary and initial conditions, and (2) a high resolution initial condition dataset in conjunction with ERA-I boundary conditions. For the new technique, we obtained a high resolution data set from the BOM TC operational forecast model Australian Community Climate and Earth System Simulator-Tropical Cyclone (ACCESS-TC) (Puri et al. 2010, 2013; Davidson et al. 2014). The data is at $0.11^{\circ}$ horizontal resolution with 50 vertical level for January 31, 2011, at 00:00 UTC. We converted the data file into WRF intermediate file format and read it in with the ERA-I data during data pre-processing to create a new forcing file for the initial time step. Figure 3 demonstrates the difference between the SLP data in the ERA-I and the ACCESS-TC data for initializing Yasi. The ACCESS-TC file did not cover the whole WRF domain, but extends from $-7:-25^{\circ} \mathrm{N}$ and $142: 171^{\circ} \mathrm{E}$ (Figure $3 \mathrm{~b}$ ). Therefore, ERA-I data was used to fill in the initial condition data in areas of the domain where ACCESS-TC data was absent. After initialization, ERA-I provides the boundary conditions. The simulations were compared in terms of intensity over the TC life cycle (central pressure and wind speed), translation speed, trajectory, and landfall location.

\subsubsection{Sensitivity to Initial Conditions}

Blending high-resolution ACCESS-TC data with the coarser ERA-I data produced a notably different track (Figure 4) and a more intense TC system (deeper central pressure and elevated wind speeds (Figure 5). Figure 4 demonstrates that there is a discrepancy between the observed IBTrACS (Knapp et al. 2010) trajectory and the trajectory present in the ERA-I reanalysis data which may be due to the coarse resolution $\left(0.7^{\circ}\right)$ of the ERA-I 
data. This highlights that error is introduced with the boundary condition dataset and the large scale forcing. Figure 4 also shows a disparity between the trajectory simulated by WRF with the ERA-I only conditions and the observed trajectory in the ERA-I data. This disparity may be attributed to uncertainties introduced through the WRF numerical modeling technique, such as parametrization choice and internal variability. Figure 4 also shows that initializing with ACCESS causes the trajectory to deviate further poleward from observed data (IBTrACS and ERA-I), and the system makes landfall $\sim 100 \mathrm{~km}$ further south than the simulation with just ERA-I for initial and boundary conditions (Table 2, Run 5 and 6). This suggests that there are additional uncertainties introduced by the ACCESS initialization data. However, the trajectory evolution with the ACCESS initialization is more consistent with observations, while the ERA-I only simulation demonstrates erroneous sinuosity compared to observations. Furthermore, the simulations where ERA-I provides both the initial and boundary conditions (Table 2, Run 1 and Run 5) produced a much faster translation speed compared to observed, affecting the simulation skill.

In preliminary analyses (not shown), initializing the WRF simulations earlier or later with the ERA-I only data for boundary and initial conditions did not improve the simulation. This is consistent with results from Shepherd and Walsh (2016) where there was some sensitivity to initialization time, but a greater sensitivity to other factors such as physical parameterizations. Furthermore, it has been found that increasing simulation lead time ( $\geq 72$ hours before landfall) can result in greater landfall location errors (Mohanty et al. 2010). Therefore, we continued our investigation of the sensitivity to initial condition resolution, with one initialization time.

Despite the increased trajectory deviation, Table 2 demonstrates that initializing with ACCESS increases the intensity and reduces the pressure error at landfall (compare Runs 1 
and 2 and Runs 5 and 6). Figure $3 \mathrm{~b}$ demonstrates there is a defined vortex structure with increasing intensity towards the eye, reaching pressures of $980 \mathrm{hPa}$, in the analysis data provided by the ACCESS-TC $\left(0.11^{\circ}\right.$ horizontal resolution $)$ initial condition file. Figure $3 \mathrm{a}$ shows that the pressure structure and intensity is comparatively not as well defined in the ERA-I $\left(0.7^{\circ}\right.$ horizontal resolution $)$ reanalysis data at this early stage of the event. This difference was fundamental for enabling the development of a more intense system (particularly the sea level pressure). We found that initializing with the higher resolution ACCESS-TC data, with no CU, MP, or PBL schemes reduces the error index from 1.20 to 0.88 through reduced deviations in all metrics (Table 2, Run 1 to Run 2, no CU, MP, PBL enabled). The simulated TCs are still very weak compared to observations regardless of initialization technique if no parameterization schemes are prescribed (Figure 5a). When physics parameters are prescribed (e.g. CU1 MP5 PBL1) but simulations differ by the initialization data method, using the ACCESS-TC data improves the skill score from 1.12 to 0.77 by reducing central pressure and translation speed errors (compare Runs 5 and 6 , Table 2). Figure 5b shows that with the CU1, MP5, PBL1, the ACCESS initialization data results in TC intensification at a rate greater than observed and maximum intensity is reached too early in the simulation. However, with this initialization, the rate of intensification, the SLP values, and intensity at landfall are more realistic and comparable to observations in contrast with the weaker system (higher central pressure values) achieved with ERA-I only. It is important to accurately capture TC intensity, particularly at landfall given potential damage to coastal areas. These results demonstrate a technique to improve translation speed and intensity simulation on a model setup with grid spacing of $36 / 12 \mathrm{~km}$ without increasing horizontal or vertical resolution, saving computational costs 
and time. Consequently, this initialization method is used for the sensitivity tests that follow.

\subsection{Physical parameterizations}

We performed an ensemble of simulations using a range of physical parameterization configurations, using otherwise identical model setups, boundary and initial conditions, and run times. The ensemble members included varying the sub-grid scale convection (CU), moist microphysics (MP), planetary boundary layer (PBL) schemes, the use of a surface flux coefficient, and a 1-dimensional ocean mixed layer model (OML) (see Table 1).

The CU parameterization simulates the effects of sub-grid scale cumulus convection on heat and moisture tendencies and rainfall (Skamarock et al. 2008). Most CU parameterizations include shallow convection, where cumulus clouds that are not deep enough to produce precipitation transport air from the mixed layer across the boundary layer inversion (Torn and Davis 2012). The overall effect is to transport moisture upwards and heat downwards (Torn and Davis 2012). In this way, these CU parameterizations vertically redistribute heat and moisture regardless of latent heating from precipitation (Nasrollahi et al. 2012). However, the closure mechanisms and activation of shallow and deep convection varies by scheme, affecting their representation of vertical heat and moisture. A total of five CU schemes were used in this ensemble (see Table 1).

The MP scheme represents the effects of grid resolved moisture physics on the atmospheric heat and moisture tendencies, the vertical flux of precipitation, and the 
sedimentation process (Skamarock et al. 2008). Five MP schemes were used in this ensemble (see Table 1).

The PBL scheme parameterizes turbulent exchanges of heat, moisture and momentum and thus governs vertical diffusion and mixing in the lower atmosphere. Two PBL schemes were tested in this ensemble (see Table 1).

Previous studies (Emanuel 1995; Braun and Tao 2000; Bao et al. 2002; Davis et al. 2008) have shown that the surface flux coefficient (ISFTCFLX), and the use of a onedimensional ocean mixed layer model (OML) can influence the model's ability to simulate the TC inner core structure, eye size, and intensity. Thus, bulk surface drag coefficients and energy exchange parameterizations have been developed in WRF for TCs over the ocean surface. The ISFTCFLX (Garratt 1994; Donelan et al. 2004) option was included in some ensemble members to test its effect. This parameterization has reduced surface drag compared to the original Charnock (1955) formulation. Furthermore, there is a potential negative feedback of wind-driven ocean mixing on TC intensity. Strong TC winds drive oceanic turbulence which is one of the dominant mechanisms for cooling the sea surface during a TC event. This cooling occurs in the vicinity of the storm and reduces the amount of heat and moisture available to the TC which in turn limits its intensity (Mooney et al. 2016). This first order negative feedback can be represented by coupling a simple onedimensional ocean mixed layer (OML) to the atmosphere within WRF (Emanuel et al. 2004). Some studies (e.g. Davis et al. 2008) have demonstrated that this coupling can improve the simulation of TC intensity and the rate of intensification, particularly in simulations where intensity was over estimated (central pressures too low) before coupling. Thus, the available OML (Pollard et al. 1972) was tested as part of the parameterization sensitivity ensemble. 
Other physical parameterizations that were held constant are as follows: shortwave radiation is calculated by the Dudhia scheme (Dudhia 1989); longwave radiation fluxes are calculated by the RRTM scheme (Mlawer et al. 1997); surface layer is from the MM5 Monin-Obukov scheme (Monin and Obukhov 1954); land surface processes and structure are defined by the Unified Noah Land Surface Model (Chen and Dudhia 2001; Ek et al. 2003; Tewari et al. 2004); and SSTs are fixed for the duration of the simulations unless otherwise stated.

\subsection{Sea Surface Temperature Boundary Conditions}

Lastly, we directly tested the sensitivity of the simulation to four different representations of SST boundary condition. (1) Daily ERA-I SSTs were provided to WRF at regular intervals (SST updating). (2) One dimensional OML (in isolation from using ISFTCFLX) was employed while allowing ERA-I SST updating. Further details of simulating TC interactions with SSTs using ERA-I and the one-dimensional OML model are described in Mooney et al. (2016). (3) Lag-corrected ERA-I SSTs, updated every 24hrs. (4) Finally, the sensitivity to a higher resolution auxiliary SST dataset was tested.

Detailed analysis of the ERA-I data by the authors has revealed that the ERA-I SSTs are lagging the atmospheric variables by 30 hours in the reanalysis data since 2009. Figure 6 of the SST fields on Feb 2 2011, demonstrates the uncorrected compared to the 30 hour ERA-I corrected data (Figure $6 \mathrm{a}, \mathrm{b}$ ). Once this SST lag has been corrected for, there are cooler SSTs beneath the path of the storm (Figure 6b) that more closely resemble the SST values and distribution present in the Operational Sea Surface Temperature and Sea Ice Analysis (OSTIA, Stark 2007) SST data set that is used for the ERA-I Reanalysis (6c). A 
TC-induced SST cold wake would be expected trailing an intense TC such as Yasi (Dare and McBride 2011; Mooney et al. 2016) but is largely missing from the ERA-I data before the lag correction (Figure 6a). The 30 hour lag is further evident in Figure 6e which shows the evolution of the SSTs averaged over a $2^{\circ}$ x $2^{\circ}$ box centred on $155^{\circ} \mathrm{E}, 15^{\circ} \mathrm{S}$. Figure $6 \mathrm{e}$ demonstrates that the SSTs values in the ERA-I reanalysis data are lagging the OSTIA observed SST values by 30h and when this time lag is corrected for, the ERA-I SST values then align with the OSTIA values. Therefore, we have tested the effect of this lag-corrected SST representation, for scenario 3 of the surface boundary condition testing.

For the fourth SST scenario with a higher resolution SST, we used the blended Microwave Optimally Interpolated SST product (hereafter referred to as REMSS) (REMSS 2013) which are daily means available on a global grid of $9 \mathrm{~km}$ spacing. We temporally interpolated the REMSS SST data into 6-hourly intervals and assimilated it into the lower boundary forcing during pre-processing to create new forcing files for the simulation. Figure 6 demonstrates that the resolution of the REMSS dataset (6d) captures more structure and detail in the SST field, particularly the area of the cold wake and some warmer SST pockets in the coastal lagoon that are absent in the ERA-I data even with lag fixed (6b). The SST sensitivity scenarios tested are summarized in Table 1 (last column). Each of these non-static SST scenarios provides a more accurate representation of the true SSTs, and therefore improve the interaction between the TC and the sea surface. We have examined whether including these improvements to the lower boundary conditions increases the simulation skill.

\subsection{Analysis methods}


Individual realizations of Yasi were assessed in terms of trajectory, landfall location, life cycle intensity (central pressure and wind speed), intensity at landfall, and translation speed. To easily compare the individual realizations, we created a new simple skill score metric using the following parameters: (1) the deviation in landfall central pressure from observed $(\mathrm{hPa}) ;(2)$ the deviation in the average translation speed of the system up to landfall $(\mathrm{km} / \mathrm{h})$; and (3) the deviation in landfall location from observed $(\mathrm{km})$. The error index for each ensemble simulation was calculated by normalized root-mean-square error of the listed parameters using Equation 1. The value chosen to normalize each parameter was the largest recorded deviation for the given parameter in all of the simulations tested.

\section{Equation 1: Simulation Skill}

$$
=\sqrt{\left(\frac{\Delta \text { LandfallPressure }}{77.170(\mathrm{hPa})}\right)^{2}+\left(\frac{\Delta \text { TranslationSpeed }}{19.920\left(\frac{\mathrm{km}}{\mathrm{h}}\right)}\right)^{2}+\left(\frac{\Delta \text { LandfallLocation }}{256.476(\mathrm{~km})}\right)^{2}}
$$

This calculation considers equally the landfall location (trajectory), central pressure (intensity), and translation speed (forward speed), allowing the simulation skill of WRF and the different combinations of physical parameterizations to be evaluated. The lowest error index indicates the most accurate simulation in the ensemble. A comprehensive list of parameter deviations and error indices for each ensemble member are given in Table 2. Skill scores inherently simplify complex datasets, but do provide a method for easily comparing a large number of ensemble members. Our skill score calculation is primarily based on TC conditions at landfall, which could be considered a narrow focus. However, it is pertinent to use landfall characteristics to calculate skill given the relationship with potential coastal damage. In addition, the use of the translation speed term in the calculation of the index considers an aspect of the TC lifecycle from initialization up to landfall, and so is not just a characteristic of the ensemble members at landfall. 
Furthermore, the spread in the ensemble results (e.g. trajectories in Figure 7) suggests that the spread in results at landfall is representative of the spread in the ensemble members throughout the simulations of the TC lifecycles. The spread in skill scores of the ensemble members was also explored using a multivariate analysis of variance (ANOVA). For the ANOVA, the changes in CU, MP, PBL, ISFTCFLX, OML, and vertical resolution are selected as the independent predictor variables, with error index score as the dependent variable. These analyses explore the mechanisms that produce the large spread between realizations.

\section{Results and Discussion}

\subsection{Sensitivity to Physics Parameterizations}

As expected, prescribing any CU, MP and PBL parameterizations (instead of default of none) greatly improved the simulation performance, and were crucial to producing TClike wind speed and pressure evolution over these simulations (compare Figure 5a-5b). Using parameterizations reduced the error index, particularly in terms of the pressure and translation speed deviation (see Table 2).

The choice of CU, MP, PBL, ISFTCFLX, OML, and vertical resolution parameterizations significantly $(\mathrm{p}=0.01)$ accounted for $\sim 91 \%$ of error index variance calculated using multivariate ANOVA. The CU and MP are the only parameterizations to individually account for the variance in error index significantly in one-way ANOVAs. MP parameterization variation accounted for $46 \%$ of the error index variation $(p=0.03)$ while 
CU parameterizations explained $66 \%$ of the variance $(\mathrm{p}=0.0005)$. Therefore, this analysis focuses primarily on the effect of the CU and MP parameterizations on the simulation.

As with other studies (e.g. Wang and Seaman 1997; Gallus 1999; Prater and Evans 2002; Zhang et al. 2011; Nasrollahi et al. 2012; Shepherd and Walsh 2016), analysis of the ensemble members highlights a distinct sensitivity of the simulation to the cumulus parameterization. Our results demonstrate a trade-off between simulating either the trajectory or intensity accurately with the choice of CU. As the simulations progress and landfall approaches, some ensemble members diverge significantly from the observed trajectory and landfall location (Figure 7). CU parameterization choices strongly influence the clustering of trajectories (Figure 7). Our independent findings did not support those of Nasrollahi et al. (2012) where BMJ produced the most accurate trajectory, or Shepherd and Walsh (2016) where there was little difference in the trajectories from the Kain Fritsch or Tiedtke schemes. Instead, our results confirm those of Torn and Davis (2012) where the ensemble members that utilize the Tiedtke parameterization (CU6, Figure 7, red) resulted in a trajectory much closer to observed than those using other parameterizations. It is particularly apparent in our results that the members with the Kain Fritsch CU scheme (CU1, Figure 7, green) systematically track further poleward, making landfall from 135 to $215 \mathrm{~km}$ further south than observed. Though the simulations with no CU scheme prescribed (Figure 7, black) achieve a more accurate landfall location than those members with the Kain Fritsch scheme (CU1, Figure 7, green), the simulated trajectory through the lifecycle up to landfall is still markedly displaced southwards (which is not captured by the index calculation). The Grell Devenyi (CU3) and Grell 3D ensemble (CU5) schemes (Table 2 Runs: 7 and 8 respectively) simulated accurate translation speeds. However, their 
trajectories and landfall locations fall between those simulated using the Tiedtke and Kain Fritsch schemes.

Previous studies (e.g. Torn and Davis 2012) have shown that shallow convection over the tropical oceans is poorly represented in the Kain Fritsch scheme and may result in a warm temperature bias at the $700 \mathrm{mb}$ level, with associated steering flow bias. Figure 8 shows the average temperature and wind at the $700 \mathrm{mb}$ level over the entire 96 hours of a simulation, with Kain Fritsch (Figure 8a) and Tiedtke (Figure 8b) CU schemes. The Kain Fristch scheme simulates temperatures $\sim 1^{\circ} \mathrm{C}$ (and up to $2^{\circ} \mathrm{C}$ ) warmer than the Tiedtke scheme. The Kain Fritsch scheme also produces a difference in the average flow, likely steering the system further poleward (Figure 8c). The active shallow convection over tropical ocean (where the moisture flux through the cloud base is assumed to be equivalent to surface moisture flux in the Tiedtke scheme (Torn and Davis 2012)) produces cooler temperatures at the $700 \mathrm{mb}$ level and an average flow that moves predominately east-west (Figure 8b). As discussed by Shepherd and Walsh (2016), beta drift (Holland 1983) can add an additional southward component of motion to the steering flow to westward moving TCs in the Southern Hemisphere. Figure 9 demonstrates that the radius of 64 knot winds was notably larger with the Kain Fritsch scheme (solid green line, Figure 9) during the main intensification period up to landfall than with the Tiedtke scheme (dashed green lines Figure 9). The larger TC size with the Kain Fritsch scheme could account for the greater drift of the system polewards due to a stronger beta effect (Holland 1983), in addition to the steering flow.

When considering both the calculated landfall location distance deviation and pressure deviation of the simulations from observed (Table 2), it is clear that while changes to ensemble members such as MP scheme, PBL scheme, vertical resolution, ISFTCFLX, 
and OML did have some effect on the outcome of the simulation, the CU parameterization remains the greatest influence particularly in terms of the resulting intensity and trajectory. Figure 10 depicts the landfall pressure deviation against the landfall distance deviation for each ensemble member. Ensemble members employing the Tiedtke scheme (CU6, Figure 10 red) cluster at the lowest landfall deviation values, indicating that this scheme is best for producing accurate trajectories. However, this scheme produces relatively high landfall pressure deviations, indicating systematically weaker TCs. Conversely, ensemble members employing the Kain Fritsch scheme (CU1, Figure 10 green) cluster at lower pressure deviations, demonstrating that this scheme achieves a more realistic pressure (and thus intensity at landfall). However, the Kain Fritsch scheme produces a relatively large landfall location deviation (greater than 130km). Therefore, there appears to be a trade-off between employing the Kain Fritsch and Tiedtke CU parameterizations that has not previously been discussed for this grid, in this location. The Tiedtke scheme produces the most accurate trajectories, while the Kain Fritsch scheme produces the most accurate intensities. Other schemes produce intermediate results (with much higher overall error indices). The significant degree of CU-dependent clustering observed indicates that these differences are systematic effects, and are not simply due to model internal variability.

Figure 9 demonstrates that the Kain Fritsch scheme (CU1, solid line) produced lower pressure values (closer to observed values of SLP, in red) and therefore a more intense system than the Tiedtke scheme which lacked deepening and intensification (CU6, dashed line) throughout the lifecycle up to landfall. These results support the intensity differences discussed in Shepherd and Walsh (2016). The active shallow convection of the Tiedtke scheme over the tropical ocean allows vertical advection of evaporation from the ocean surface and upward transport of moisture across the boundary layer (Torn and Davis 2012). 
However, the shallow convection can reduce the deep convective mass flux and buoyancy, resulting in reduced TC intensification rate (Torn and Davis 2012). This reduction would account for the reduced central pressure achieved by the ensemble members with the Tiedtke scheme in this study. Conversely, without the shallow convection over the tropical oceans (Torn and Davis 2012), the Kain Fritsch scheme may be less likely to reduce the deep convective mass flux and allow intensification rate increase resulting in systems with greater intensity.

To further evaluate the Tiedtke and Kain Fritsch schemes, we investigate the accuracy of translation speed, as well as the overall error indices. As seen in Table 2, ensemble members employing the Kain Fritsch scheme had systematically lower deviations in translation speed than those employing the Tiedtke scheme. However, the Kain Fritsch ensemble members have larger overall error indices than the Tiedtke ensemble members, indicating that these error indices are dominated by deviations in trajectory.

Changing the MP parameterization with an otherwise fixed model configuration (compare Runs 9, 13, 14, and 15 in Table 2) did affect the outcome of the error index calculation. However, discerning the effect may be somewhat difficult, as the dominant influence of the shallow convection scheme in the CU parameterization can mask that of the MP scheme (Torn and Davis 2012). Notably, the WSM 5-class scheme (MP4) results in a reduced error index, primarily due to improving the simulated trajectory and landfall deviation (Table 2, Run 13). However, the Ferrier new Eta scheme (MP5) results in the lowest error index through reduced translation speed error and pressure deviation (Table 2, 
Run 9). We chose to continue further simulations with the Ferrier scheme (MP5) because it is designed for computational efficiency.

The choice of CU and MP scheme influenced the simulation sensitivity to other parameterizations such as the PBL, ISFTCFLX, and OML in the ensemble members. The results did not demonstrate a consistent effect of the PBL on the calculated skill score nor a consistent improvement when employing the ISFTCFLX in this ensemble setup.

Therefore, the YSU PBL scheme with no ISTCFLX surface drag coefficient setup was chosen for further simulations. The YSU PBL is a first order closure scheme (Noh et al. 2003) and is often less biased toward excessive mixing (Braun and Tao 2000) and so is favored from this ensemble. 
The ensemble members with the Kain Fritsch CU scheme are comparatively the most successful at simulating intensity evolution and pressure at landfall. However, as with the ACCESS-TC forecasts (Reeder et al. 2012), none of our model configurations thus far were able to reproduce the maximum observed intensity of TC Yasi or maintain intensity towards landfall. For almost all ensemble members, the minimum in central pressure occurred too early over the open ocean around 08:00 UTC on February 1, 2011, and then weakened towards landfall. This under-representation of intensity could be expected with a relatively coarse horizontal resolution of $12 \mathrm{~km}$ (Gentry and Lackmann 2010). However, TC intensity is strongly linked to SSTs (Schade and Emanuel 1999; Ramsay and Sobel 2011). Therefore, we have tested the simulation sensitivity to the SST boundary condition. In particular, the sensitivity to the SST dataset resolution and SST interaction with the atmosphere, which will now be discussed.

\subsection{Sensitivity to SST Boundary Conditions}

In previous simulations, the SSTs were constant throughout the entire simulation. However, this is physically unrealistic as TCs interact with the ocean surface, cooling surface temperatures within hours of their arrival (Dare and McBride 2011; Mooney et al. 2016). This is particularly important for TC intensity, as cooling near the cyclone reduces heat and moisture available to the system, thus dampening the intensity. Therefore, nonstatic SST boundary conditions may improve the simulations. Here, we investigate the sensitivity of Yasi simulations to four different representations of SST (detailed in Section 2.4): (1) daily SSTs derived from ERA-I, (2) active interaction between TC and SST via a 
1-D ocean mixed layer model, (3) daily SSTs derived from ERA-I with 30hr lag corrected, and (4) 6-hourly SSTs derived from higher resolution REMSS data. A change in the spatial distribution and representation of the SSTs could be important for controlling the intensification of TC Yasi, particularly in the coastal lagoon area (Bosart et al. 2000; Hong et al. 2000; and Mainelli et al. 2008).

Figure 11c and d show that allowing SST to update during the simulation and then making further changes to the SST representation, results in significant deviations in the SSTs observed under the center of the TC systems (compare colored lines to black line). The simulations of TC Yasi with the Kain Fritsch scheme are relatively insensitive to the changes made to the SST boundary. The trajectories (Figure 11 a) and intensities (Figure 11 e) are relatively stable (see also Table 2, Runs 33-37) with the results from the simulations tightly clustered. The changes to the SST representation have a common effect of reducing landfall location error slightly and increasing intensity. The increased intensity is particularly notable for the ERA-I lag fix scenario (Figure 11e green) and may be attributed to the increased SST values under the storm particularly between $25 \mathrm{~h}$ and $45 \mathrm{~h}$ of simulation time (Figure 11c).

Given the same changes to the SST boundary, simulated trajectories with the Tiedtke scheme show a slightly larger spread (Table 2, Runs 28-32; Figure 11 b). The different SSTs encountered by the TC (Figure $11 \mathrm{~d}$ ) contribute to comparatively greater differences in intensity through the TC lifecycle, with significant increases in intensity of up to $\sim 10 \mathrm{hPa}$ from $30 \mathrm{~h}$ to landfall (Figure $11 \mathrm{f}$ ). The tested scenarios should improve the physical representation of the TC-ocean interaction and improve the representation of the TCinduced cool wake in the WRF simulation. The ocean interaction and cold wake did not dampen or reduced TC intensity as may have been expected, but in fact increases intensity 
from the fixed SST simulation for both CU schemes (Figure 11e,f). This may be attributed to the forward speed of Yasi which enabled the system to interact with warmer SSTs (Figure $11 \mathrm{c}, \mathrm{d}$ ) ahead of the TC-induced cold wake.

In the Tiedtke scheme, deep and shallow convection are both governed by moisture flux (Qiao and Liang 2015). Convection is activated when moisture convergence exceeds a limit of boundary layer turbulent moisture flux (Qiao and Liang 2015). The Tiedtke scheme may therefore have greater sensitivity to changes in the boundary SSTs (and the associated evaporation and moisture) than the Kain Fritsch scheme, which is triggered by column convective instability and parcel temperature (Qiao and Liang 2015). As discussed in section 3.1, the Tiedtke scheme has a more appropriate and active treatment of shallow oceanic convection where the moisture flux through the cloud base is assumed to be equivalent to surface moisture flux (Torn and Davis 2012). The shallow convection allows vertical advection of evaporation from the ocean surface and upward transport of moisture across the boundary layer (Torn and Davis 2012). This shallow convection parameterization is appropriate for tropical oceans, even during hurricane winds, and may account for the greater sensitivity to the SST boundary conditions over the ocean.

Conversely, the Kain Fritsch scheme performs better over land surfaces, but its inadequate representation of shallow convection over tropical oceans may make it less responsive to changes in the SST boundary (Torn and Davis 2012).

Table 2 shows that the intensity at landfall is sensitive to the SSTs. The ERA-I lag fix improved intensity for the Kain Fritsch scheme (Figure 11e) but the higher resolution REMSS SSTs improve the simulated intensity regardless of the CU scheme used. This increased intensity is primarily responsible for improving the error index. We focus this 
discussion on the Tiedtke simulations as the improvement in intensity is more evident. From time step 42 to 60 , the simulated TC tracked over warmer SST values using REMSS SSTs (Figure $11 \mathrm{~d}$ red line) than when using the ERA-I SSTs (Figure $11 \mathrm{~d}$ other colors). The increased SST gradient destabilizes the overlying atmosphere and increases the upper limit of TC intensity (Vecchi and Soden 2007). The surface fluxes of heat and moisture, and vigorous convection increase in concert with SST values. Vertical mass flux and acceleration are subsequently enhanced and the inward mass convergence results in enhanced vorticity convergence and vortex stretching. Upper-level thermal expansion develops along with the upper-level vortex intensification. These system-scale changes cause increases in relative vorticity and rapid intensification of the TC system (Garner et al. 2009). Figure 12 demonstrates that with both the Kain Fritsch and Tiedtke schemes, the REMSS SST data set acted to increase the relative vorticity at the $500 \mathrm{hPa}$ level. For the Kain Fritsch scheme (Figure 12a), the increased values of relative vorticity are tightly confined around the TC eye. There was a greater system-scale response of the relative vorticity to altered SST forcing with the Tiedtke scheme (Figure 12b). There were more discernible changes in values within the eye and over the whole cross section of the system for this CU scheme, further indicating a greater sensitivity to the change in the SST boundary condition.

At higher grid spacing, where convection is explicitly resolved, it is expected that simulation responses to SST changes would be influenced by the PBL schemes. Li and Pu (2008, 2009) showed that, for hurricane Emily, CU were the most influential at 9km grid spacing whereas the PBL schemes were the most influential at grid spacing of $3 \mathrm{~km}$. This demonstrates that at the convection resolving scales, PBL schemes are an important consideration while at the grid spacing used in this study, the CU are more influential. 


\section{Conclusions}

Tropical Cyclone Yasi was a rapidly-intensifying and long-lived category 5 system, the first to cross the Queensland coastline in nearly a century. It is important to improve the representation of such TC cases on a relatively coarse grid to inform model configuration for future regional climate simulations. While the results from sensitivity testing on this grid may not translate to future simulations over long time periods, the results could be used in future simulations of extreme events. Yasi's maximum intensity and intensity evolution towards landfall proved difficult to simulate with the numerical weather model (WRF) in a $36 \mathrm{~km}$ and $12 \mathrm{~km}$ nested domain configuration. However, this study successfully represents the TC's characteristics on this grid using ERA-Interim data as boundary conditions, ACCESS-TC high resolution data for initialization, optimized physics parameterizations after ensemble testing, and a high resolution SST boundary condition after SST sensitivity testing.

This study finds a distinct simulation sensitivity to the spatial resolution of the initial conditions. Results demonstrated that the simulation accuracy (particularly the intensity and translation speed) of TCs at the horizontal resolution of $36 / 12 \mathrm{~km}$ and with 28 vertical levels can be improved with an accurate and high resolution initial condition field. This is advantageous, as it is computationally cheaper than other methods, such as increasing model resolution (e.g. Gentry and Lackmann 2010; Shepherd and Walsh 2016) or large scale data assimilation (e.g. Torn and Davis 2012). This initialization method and 
model setup may be valuable to future regional climate studies that require large numbers of simulations to explore the response of TC dynamics over long time scales.

Of the physical parameterizations tested, the Yasi simulations were particularly sensitive to the cumulus parameterization, resulting in a trade-off between accurately simulating trajectory or accurately simulating intensity. The Tiedtke scheme supported a skillful trajectory evolution and landfall location, but a propagation speed faster than observed, and an overall weaker system. Conversely, the Kain Fritsch scheme simulated track and landfall location poorly, but the simulations produced more accurate intensities and translation speeds over the TC lifecycle. Several of these differences can be attributed to the CU schemes' representation of shallow convection over the tropical ocean. The Kain Fritsch scheme lacked shallow convection, leading to warmer temperatures at $700 \mathrm{hPa}$, and ultimately a poleward bias in the average steering flow. The more active shallow convection of the Tiedtke scheme resulted in more accurate steering flows but reduced deep convective mass flux, and subsequently, intensity. These findings may inform the physics parameterization choices for future studies of TC dynamics at this resolution, depending on whether intensity or trajectory is the primary focus.

No simulation on this grid, regardless of configuration, was able to successfully reproduce the $929 \mathrm{hPa}$ minimum central pressure of Yasi, or it's intensification towards landfall. The correction of a newly discovered 30h lag in SSTs in the ERA-I reanalysis data reduced the trajectory error for simulations with the Tiedtke schemes and intensity errors with Kain Fritsch. However, the inclusion of a high-resolution, daily SST product improved the track, landfall location, and intensity of the TC simulation for both CU schemes. Altering the SST forcing resulted in a greater change to simulated intensity with 
the Tiedtke scheme due to heightened alteration in the relative vorticity in response to the added thermal energy in the boundary condition. The greater sensitivity of the Tiedtke scheme stems from the moisture convergence trigger function and the more active shallow convection over the tropical ocean than the Kain Fritsch scheme. The differing sensitivities of the scheme to the surface forcing may be an important consideration when selecting a cumulus parameterization in a model setup for future studies, particularly those that consider climate change forcing.

SST sensitivity simulations demonstrate that additional warming in the boundary condition resulted in increased TC intensity. It follows that providing accurate SSTs is essential to accurately simulating intensity, particularly towards landfall. Additional warming may have been present in the coastal lagoon during TC Yasi due to the East Australian Current (EAC), a "broad, warm tongue of water that extends southwards" (Ridgway 2007) and transports warm equatorial water into the Coral Sea (Lough 1998). The EAC exhibits non-linearity and large inter-annual variability (Foster et al. 2014), and a warm phase may not have been captured in the SST data in this region due to poor resolution, measurement error, and systematic cool bias of satellite data over Australia (particularly during times of high cloud prevalence in the summer season) (Foster et al. 2014). If SSTs were indeed underestimated during Yasi, our SST boundary condition simulations suggest that this could account for the underestimation of TC intensity through the coastal lagoon into landfall. The resolution and accuracy of SST data will also be very important in future TC intensity simulations and predictions, given that SSTs have been rising in this region already (Hughes et al. 2003; Foster et al. 2014) and will likely continue with climate change forcings (Hughes et al. 2003). 


\section{Acknowledgements}

The authors would like to thank Todd Arbetter at the Institute for Environment and Society at Brown University for invaluable assistance in pre-processing and post-processing; Henry Johnson for assistance implementing WRF on Brown University's Center for Computing and Visualization; Noel Davidson at the Australian Bureau of Meteorology for the high resolution initialization data and advice; Jung-Eun Lee at Brown University, and Greg Holland at the National Center of Atmospheric Research for helpful discussion; and Daniel P Moriarty III at Brown University for assistance in editing the manuscript. This work was funded by Brown University. NCAR is sponsored by the National Science Foundation. 


\section{References}

1. Abarca, S. F., \& Corbosiero, K. L. (2011). Secondary eyewall formation in WRF simulations of Hurricanes Rita and Katrina (2005). Geophysical Research Letters, 38(7).

2. Alexander, L. V., Hope, P., Collins, D., Trewin, B., Lynch, A., \& Nicholls, N. (2007). Trends in Australia's climate means and extremes: a global context. Australian Meteorological Magazine, $56(1), 1-18$.

3. AON Benfield, (2011)

http://thoughtleadership.aonbenfield.com/Documents/201103_ab_if_tropical_cyclone_yasi_recap .pdf

4. Australian Bureau of Meteorology, (2011) [http://www.bom.gov.au/cyclone/history/yasi.shtml];

5. Bao, J. W., Gopalakrishnan, S. G., Michelson, S. A., Marks, F. D., \& Montgomery, M. T. (2012). Impact of Physics Representations in the HWRFX on Simulated Hurricane Structure and Pressure-Wind Relationships. Monthly Weather Review, 140(10), 3278-3299.

6. Bao, J. W., Michelson, S. A., \& Wilczak, J. M. (2002). Sensitivity of numerical simulations to parameterizations of roughness for surface heat fluxes at high winds over the sea. Monthly weather review, 130(7), 1926-1932.

7. Beeden R, Maynard J, Puotinen M, Marshall P, Dryden J, Goldberg J, et al. (2015). Impacts and Recovery from Severe Tropical Cyclone Yasi on the Great Barrier Reef. PLoS ONE 10(4): e0121272. doi:10.1371/journal.pone.0121272

8. Bosart, L. F., Bracken, W. E., Molinari, J., Velden, C. S., \& Black, P. G. (2000). Environmental influences on the rapid intensification of Hurricane Opal (1995) over the Gulf of Mexico. Monthly weather review, 128(2), 322-352.

9. Braun, S. A., \& Tao, W. K. (2000). Sensitivity of high-resolution simulations of Hurricane Bob (1991) to planetary boundary layer parameterizations. Monthly Weather Review, 128(12), 39413961. 
10. Bruyère, C. L., Holland, G. J., \& Towler, E. (2012). Investigating the use of a genesis potential index for tropical cyclones in the North Atlantic basin. Journal of Climate, 25(24), 8611-8626.

11. Charnock, H. (1955). Wind stress on a water surface. Quarterly Journal of the Royal Meteorological Society, 81(350), 639-640.

12. Chen, F., \& Dudhia, J. (2001). Coupling an advanced land surface-hydrology model with the Penn State-NCAR MM5 modeling system. Part I: Model implementation and sensitivity. Monthly Weather Review, 129(4), 569-585.

13. Dare, R. A., \& McBride, J. L. (2011). Sea surface temperature response to tropical cyclones. Monthly Weather Review, 139(12), 3798-3808.

14. Davidson, N. E., Xiao, Y., Ma, Y., Weber, H. C., Sun, X., Rikus, L. J., ... \& Fraser, J. (2014). ACCESS-TC: Vortex specification, 4DVAR initialization, verification, and structure diagnostics. Monthly Weather Review, 142(3), 1265-1289.

15. Davis, C., Wang, W., Chen, S. S., Chen, Y., Corbosiero, K., DeMaria, M., ... \& Xiao, Q. (2008). Prediction of landfalling hurricanes with the Advanced Hurricane WRF model. Monthly Weather Review, 136(6), 1990-2005.

16. Dee, D. P., and Coauthors, (2011): The ERA-Interim reanalysis: Configuration and performance of the data assimilation system. Quart. J. Roy. Meteor. Soc., 137, 553-597.

17. Done, J.M., Holland, G.J., Bruyère, C.L., Leung, L.R., and Suzuki-Parker, A., 2013: Modeling high-impact weather and climate: Lessons from a tropical cyclone perspective. Climatic Change, doi: 10.1007/s10584-013-0954-6

18. Donelan, M. A., Hamilton, J., \& Hui, W. H. BK Haus, N. Reul, WJ Plant, M. Stiassnie, HC Graber, OB Brown, and ES Saltzman, (2004): On the limiting aerodynamic roughness of the ocean in very strong winds. Geophys. Res. Lett, 31, L18306.

19. Dudhia, J. (1989). Numerical study of convection observed during the winter monsoon experiment using a mesoscale two-dimensional model. Journal of the Atmospheric Sciences, 46(20), 3077-3107. 
20. Ek, M. B., Mitchell, K. E., Lin, Y., Rogers, E., Grunmann, P., Koren, V., ... \& Tarpley, J. D. (2003). Implementation of Noah land surface model advances in the National Centers for Environmental Prediction operational mesoscale Eta model. Journal of Geophysical Research: Atmospheres (1984-2012), 108(D22).

21. Emanuel, K. A. (1995). Sensitivity of tropical cyclones to surface exchange coefficients and a revised steady-state model incorporating eye dynamics. Journal of the Atmospheric Sciences, 52(22), 3969-3976.

22. Emanuel, K., DesAutels, C., Holloway, C., \& Korty, R. (2004). Environmental control of tropical cyclone intensity. Journal of the atmospheric sciences, 61(7), 843-858.

23. Ferrier, B. S. (1994). A double-moment multiple-phase four-class bulk ice scheme. Part I: Description. Journal of the atmospheric sciences, 51(2), 249-280.

24. Ferrier, B. S., Y. Jin, Y. Lin, T. Black, E. Rogers, and G. DiMego, (2002). Implementation of a new grid-scale cloud and rainfall scheme in the NCEP Eta Model. Preprints, 15th Conf. on Numerical Weather Prediction, San Antonio, TX, Amer. Meteor. Soc., 280-283.

25. Fierro, A. O., Rogers, R. F., Marks, F. D., \& Nolan, D. S. (2009). The impact of horizontal grid spacing on the microphysical and kinematic structures of strong tropical cyclones simulated with the WRF-ARW model. Monthly Weather Review, 137(11), 3717-3743.

26. Foster, S. D., Griffin, D. A., \& Dunstan, P. K. (2014). Twenty Years of High-Resolution Sea Surface Temperature Imagery around Australia: Inter-Annual and Annual Variability. PloS one, 9(7), e100762.

27. Fovell, R. G., \& Su, H. (2007). Impact of cloud microphysics on hurricane track forecasts. Geophysical Research Letters, 34(24).

28. Fovell, R. G., Corbosiero, K. L., \& Kuo, H. C. (2009). Cloud microphysics impact on hurricane track as revealed in idealized experiments. Journal of the Atmospheric Sciences, 66(6), 17641778. 
29. Gallus Jr, W. A. (1999). Eta simulations of three extreme precipitation events: Sensitivity to resolution and convective parameterization. Weather and forecasting, 14(3), 405-426.

30. Garner, S. T., Held, I. M., Knutson, T., \& Sirutis, J. (2009). The roles of wind shear and thermal stratification in past and projected changes of Atlantic tropical cyclone activity. Journal of Climate, 22(17), 4723-4734.

31. Garratt, J. R. (1994). The atmospheric boundary layer. Cambridge university press.

32. Gentry, M. S., \& Lackmann, G. M. (2010). Sensitivity of simulated tropical cyclone structure and intensity to horizontal resolution. Monthly Weather Review, 138(3), 688-704.

33. Glisan, J. M., Gutowski Jr, W. J., Cassano, J. J., \& Higgins, M. E. (2013). Effects of spectral nudging in WRF on Arctic temperature and precipitation simulations. Journal of Climate, 26(12), 3985-3999.

34. Great Barrier Reef Marine Park Authority (2011a), Extreme Weather and the Great Barrier Reef, 2011, GBRMPA, Townsville.

35. Great Barrier Reef Marine Park Authority (2011b), Impacts of tropical cyclone Yasi on the Great Barrier Reef: a report on the findings of a rapid ecological impact assessment, July 2011, GBRMPA, Townsville.

36. Grell, G. A. (1993). Prognostic evaluation of assumptions used by cumulus parameterizations. Monthly Weather Review, 121(3), 764-787.

37. Grell, G. A., \& Dévényi, D. (2002). A generalized approach to parameterizing convection combining ensemble and data assimilation techniques. Geophysical Research Letters, 29(14), 381.

38. Holland, G. J. (1983). Tropical cyclone motion: Environmental interaction plus a beta effect. Journal of the Atmospheric Sciences, 40(2), 328-342.

39. Holland, G., \& Bruyère, C. L. (2013). Recent intense hurricane response to global climate change. Climate Dynamics, 1-11. 
40. Hong, S. Y., \& Lim, J. O. J. (2006). The WRF single-moment 6-class microphysics scheme (WSM6). J. Korean Meteor. Soc, 42(2), 129-151.

41. Hong, S. Y., Dudhia, J., \& Chen, S. H. (2004). A revised approach to ice microphysical processes for the bulk parameterization of clouds and precipitation. Monthly Weather Review, 132(1), 103120.

42. Hong, S. Y., Noh, Y., \& Dudhia, J. (2006). A new vertical diffusion package with an explicit treatment of entrainment processes. Monthly Weather Review, 134(9), 2318-2341.

43. Hong, X., Chang, S. W., Raman, S., Shay, L. K., \& Hodur, R. (2000). The interaction between Hurricane Opal (1995) and a warm core ring in the Gulf of Mexico. Monthly Weather Review, 128(5), 1347-1365.

44. Hughes, L. (2003). Climate change and Australia: trends, projections and impacts. Austral Ecology, 28(4), 423-443.

45. Irish, J. L., \& Resio, D. T. (2010). A hydrodynamics-based surge scale for hurricanes. Ocean Engineering, 37(1), 69-81.

46. Jacob, D., J. Petersen, J., Eggert, B., Alias, A., Christensen, O.B., Bouwer, L.M., Braun, A., Colette, A., Deque, M., Georgievski, G., Georgopoulou, E., Gobiet, A., Menut, L., Nikulin, G., Haensler, A., Hempelmann, N., Jones, C., Keuler, K., Kovats, S., Kroner, N., Kotlarski, S., Kriegsmann, A., Martin, E., van Meijgaard, R., Moseley, C., Pfeifer, S., Preuschmann, S., Radermacher, C., Radtke, K., Rechid, D., Rounsevell, M., Samuelsson, P., Somot, S., Soussana, J-F., Teichmann, C., Valentini, R., Vautard, R., Weber, B. \& Yiou, P. (2014). EURO-CORDEX: new high-resolution climate change projections for European impact research. Regional Environmental Change, 14(2), 563-578.

47. Janjić, Z. I. (1994). The step-mountain eta coordinate model: Further developments of the convection, viscous sublayer, and turbulence closure schemes. Monthly Weather Review, 122(5), 927-945. 
48. Janjić, Z. I. (2002). Nonsingular implementation of the Mellor-Yamada level 2.5 scheme in the NCEP Meso model. NCEP office note, 437, 61.

49. Kain, J. S. (1993). Convective parameterization for mesoscale models: The Kain Fritsch scheme. The representation of cumulus convection in numerical models, Meteor. Monogr, 46, 165-170.

50. Kain, J.S., (2004): The Kain-Fritsch convective parameterization: An update. J. Appl. Meteor. Climatol., 43, 170-181.

51. Kain, J.S., and J.M. Fritsch, (1990): A one-dimensional entraining detraining plume model and its application in convective parameterization. J. Atmos. Sci., 47, 2784-2802.

52. Kessler, E. (1969). On the distribution and continuity of water substance in atmospheric circulation. Meteorological Monograph, 10.

53. Knapp, K. R., Kruk, M. C., Levinson, D. H., Diamond, H. J., \& Neumann, C. J. (2010). The international best track archive for climate stewardship (IBTrACS) unifying tropical cyclone data. Bulletin of the American Meteorological Society, 91(3), 363-376.

54. Kuleshov, Y., Fawcett, R., Qi, L., Trewin, B., Jones, D., McBride, J., \& Ramsay, H. (2010). Trends in tropical cyclones in the South Indian Ocean and the South Pacific Ocean. Journal of Geophysical Research: Atmospheres, 115(D1).

55. Lackmann, G. M. (2015). Hurricane Sandy before 1900 and after 2100. Bulletin of the American Meteorological Society, 96(4), 547-560

56. Landsea, C. W., Vecchi, G. A., Bengtsson, L., \& Knutson, T. R. (2010). Impact of duration thresholds on Atlantic tropical cyclone counts. Journal of Climate, 23(10), 2508-2519.

57. Lavender, S. L., \& Walsh, K. J. E. (2011). Dynamically downscaled simulations of Australian region tropical cyclones in current and future climates. Geophysical Research Letters, 38(10).

58. Li X, Pu Z. (2009). Sensitivity of numerical simulations of the early rapid intensification of Hurricane Emily to cumulus parameterization schemes in different model horizontal resolutions. J. Meteorol. Soc. Japan 87 403-421. 
59. Li, X., \& Pu, Z. (2008). Sensitivity of numerical simulation of early rapid intensification of Hurricane Emily (2005) to cloud microphysical and planetary boundary layer parameterizations. Monthly Weather Review, 136(12), 4819-4838.

60. Lough, J. M. (1998). Coastal climate of northwest Australia and comparisons with the Great Barrier Reef: 1960 to 1992. Coral Reefs, 17(4), 351-367.

61. Lynch, A., Nicholls, N., Alexander, L., \& Griggs, D. (2008). Defining the impacts of climate change on extreme events. Garnaut Climate Change Review.

62. Lynn, B. H., Healy, R., \& Druyan, L. M. (2009). Investigation of Hurricane Katrina characteristics for future, warmer climates. Climate Research, 39(1), 75-86.

63. Ma, Z., Fei, J., Huang, X., \& Cheng, X. (2012). Sensitivity of tropical cyclone intensity and structure to vertical resolution in WRF. Asia-Pacific Journal of Atmospheric Sciences, 48(1), 6781.

64. Mainelli, M., DeMaria, M., Shay, L. K., \& Goni, G. (2008). Application of oceanic heat content estimation to operational forecasting of recent Atlantic category 5 hurricanes. Weather and Forecasting, 23(1), 3-16.

65. Miglietta, M. M., Moscatello, A., Conte, D., Mannarini, G., Lacorata, G., \& Rotunno, R. (2011). Numerical analysis of a Mediterranean 'hurricane'over south-eastern Italy: sensitivity experiments to sea surface temperature. Atmospheric Research, 101(1), 412-426.

66. Mlawer, E. J., Taubman, S. J., Brown, P. D., Iacono, M. J., \& Clough, S. A. (1997). Radiative transfer for inhomogeneous atmospheres: RRTM, a validated correlated-k model for the longwave. Journal of geophysical research, 102(D14), 16663-16.

67. Mohanty, U. C., Osuri, K. K., Routray, A., Mohapatra, M., \& Pattanayak, S. (2010). Simulation of Bay of Bengal tropical cyclones with WRF model: Impact of initial and boundary conditions. Marine Geodesy, 33(4), 294-314.

68. Monin, A. S., \& Obukhov, A. (1954). Basic laws of turbulent mixing in the surface layer of the atmosphere. Contrib. Geophys. Inst. Acad. Sci. USSR, 151, 163-187. 
69. Mooney, P. A., Gill, D. O., Mulligan, F. J., \& Bruyère, C. L. (2016). Hurricane simulation using different representations of atmosphere-ocean interaction: the case of Irene (2011). Atmospheric Science Letters, 17(7), 415-421.

70. Nakanishi, M., \& Niino, H. (2009). Development of an improved turbulence closure model for the atmospheric boundary layer. 気象集誌, 87(5), 895-912.

71. Nasrollahi, N., AghaKouchak, A., Li, J., Gao, X., Hsu, K., \& Sorooshian, S. (2012). Assessing the Impacts of Different WRF Precipitation Physics in Hurricane Simulations. Weather and Forecasting, 27(4), 1003-1016.

72. Nguyen, K. C., \& Walsh, K. J. E. (2001). Interannual, decadal, and transient greenhouse simulation of tropical cyclone-like vortices in a regional climate model of the South Pacific. Journal of Climate, 14(13), 3043-3054.

73. Nicholls, N., Landsea, C., \& Gill, J. (1998). Recent trends in Australian region tropical cyclone activity. Meteorology and Atmospheric Physics, 65(3-4), 197-205.

74. Noh, Y., Cheon, W. G., Hong, S. Y., \& Raasch, S. (2003). Improvement of the K-profile model for the planetary boundary layer based on large eddy simulation data. Boundary-layer meteorology, 107(2), 401-427.

75. Oouchi, K., Yoshimura, J., Yoshimura, H., Mizuta, R., Kusunoki, S., \& Akira, N. O. D. A. (2006). Tropical cyclone climatology in a global-warming climate as simulated in a $20 \mathrm{~km}$-mesh global atmospheric model: Frequency and wind intensity analyses. Journal of the Meteorological Society of Japan. Ser. II, 84(2), 259-276.

76. Peng, M., Xie, L., \& Pietrafesa, L. J. (2004). A numerical study of storm surge and inundation in the Croatan-Albemarle-Pamlico Estuary System. Estuarine, Coastal and Shelf Science, 59(1), $121-137$

77. Pollard, R. T., Rhines, P. B., \& Thompson, R. O. (1972). The deepening of the wind-mixed layer. Geophysical \& Astrophysical Fluid Dynamics, 4(1), 381-404. 
78. Prater, B. E., \& Evans, J. L. (2002). Sensitivity of modeled tropical cyclone track and structure of hurricane Irene (1999) to the convective parameterization scheme. Meteorology and Atmospheric Physics, 80(1-4), 103-115.

79. Puotinen, M. L. (2007). Modelling the risk of cyclone wave damage to coral reefs using GIS: a case study of the Great Barrier Reef, 1969-2003. International Journal of Geographical Information Science, 21(1), 97-120.

80. Puotinen, M. M., Done, T. T., \& Skelley, W. (1997). An atlas of tropical cyclones in the Great Barrier Reef region: 1969-1997.

81. Puri, K., Dietachmayer, G., Steinle, P., Dix, M., Rikus, L., Logan, L., ... \& Bermous, I. (2013). Implementation of the initial ACCESS numerical weather prediction system. Aust. Meteorol. Oceanogr. J, 63, 265-284.

82. Puri, K., Xiao, Y., Sun, X., Lee, J., Engel, C., Steinle, P., ... \& Bowen, R. (2010). Preliminary results from Numerical Weather Prediction implementation of ACCESS. CAWCR Research Letters, 5, 15-22.

83. Qiao, F., \& Liang, X. Z. (2015). Effects of cumulus parameterizations on predictions of summer flood in the Central United States. Climate Dynamics, 45(3-4), 727-744.

84. Queensland Government (2012). Budget Strategy and Outloook 2011-2012, 70 pp, Accessed January 5 2015. [http://www.budget.qld.gov.au/current-budget/budget-papers/index.php]

85. Ramsay, H. A., \& Sobel, A. H. (2011). Effects of relative and absolute sea surface temperature on tropical cyclone potential intensity using a single-column model. Journal of Climate, 24(1), 183193.

86. Reeder, M. J., Davidson, N. E., Bishop, C. H., Kepert, J. D., Steinle, P., Tory, K. J., ... \& Chen, Y. J. (2012). Annual Report FY2012 ONRBAA09-012.

87. Rego, J. L., \& Li, C. (2009). On the importance of the forward speed of hurricanes in storm surge forecasting: A numerical study. Geophysical Research Letters, 36(7). 
88. REMSS (2013) accessed September 12013

[http://www.remss.com/sst/microwave_oi_sst_data_description.html]

89. Reuters (2015) Cyclone Yasi to cost insurers AUS \$3.5 bln forecaster. [Available online at http://www.reuters.com/article/2011/02/03/insured-losses-yasi-idUSLDE7121NR20110203]

90. Ridgway, K. R. (2007). Long-term trend and decadal variability of the southward penetration of the East Australian Current. Geophysical Research Letters, 34(13).

91. Schade, L. R., \& Emanuel, K. A. (1999). The ocean's effect on the intensity of tropical cyclones: Results from a simple coupled atmosphere-ocean model. Journal of the atmospheric sciences, $56(4), 642-651$.

92. Shapiro, L. J. (1983). The asymmetric boundary layer flow under a translating hurricane. Journal of the Atmospheric Sciences, 40(8), 1984-1998.

93. Shepherd, T. J., \& Walsh, K. J. (2016) Sensitivity of hurricane track to cumulus parameterization schemes in the WRF model for three intense tropical cyclones: impact of convective asymmetry. Meteorology and Atmospheric Physics, 1-30.

94. Skamarock, W. C., Klemp, J. B., Dudhia, J., Gill, D. O., \& Barker, D. M. (2005). Coauthors, 2008: A description of the Advanced Research WRF version 3. NCAR Tech. Note NCAR/TN475+ STR, 113.

95. Smith, R. K., \& Thomsen, G. L. (2010). Dependence of tropical-cyclone intensification on the boundary layer representation in a numerical model. Quarterly Journal of the Royal Meteorological Society, 136(652), 1671-1685.

96. Smith, R. K., Montgomery, M. T., \& Thomsen, G. L. (2013). Sensitivity of tropical-cyclone models to the surface drag coefficient in different boundary-layer schemes. Quarterly Journal of the Royal Meteorological Society.

97. Stark, J. D., Donlon, C. J., Martin, M. J., \& McCulloch, M. E. (2007, June). OSTIA: An operational, high resolution, real time, global sea surface temperature analysis system. In Oceans 2007Europe (pp. 1-4). IEEE. 
98. Tao, W. K., Shi, J. J., Chen, S. S., Lang, S., Lin, P. L., Hong, S. Y., ... \& Hou, A. (2011). The impact of microphysical schemes on hurricane intensity and track. Asia-Pacific Journal of Atmospheric Sciences, 47(1), 1-16.

99. Tewari, M., Chen, F., Wang, W., Dudhia, J., LeMone, M. A., Mitchell, K., ... \& Cuenca, R. H. (2004, January). Implementation and verification of the unified NOAH land surface model in the WRF model. In 20th conference on weather analysis and forecasting/16th conference on numerical weather prediction (pp. 11-15).

100. Thompson, G., Field, P. R., Rasmussen, R. M., \& Hall, W. D. (2008). Explicit forecasts of winter precipitation using an improved bulk microphysics scheme. Part II: Implementation of a new snow parameterization. Monthly Weather Review, 136(12), 5095-5115.

101. Thompson, G., Rasmussen, R. M., \& Manning, K. (2004). Explicit forecasts of winter precipitation using an improved bulk microphysics scheme. Part I: Description and sensitivity analysis. Monthly Weather Review, 132(2), 519-542.

102. Tiedtke, M., (1989): A comprehensive mass flux scheme for cumulus parameterization in largescale models. Mon. Wea. Rev., 117, 1779-1800.

103. Torn, R.D. \& Davis, D.A. (2012): The Influence of Shallow Convection on Tropical Cyclone Track Forecasts. Mon. Wea. Rev., 140, 2188-2197.

104. Vecchi, G. A., \& Soden, B. J. (2007). Effect of remote sea surface temperature change on tropical cyclone potential intensity. Nature, 450(7172), 1066-1070.

105. Walsh, K. (2004). Tropical cyclones and climate change: unresolved issues. Climate Research, 27(1), 77-83.

106. Walsh, K. (2015). Fine resolution simulations of the effect of climate change on tropical cyclones in the South Pacific. Climate Dynamics, 45(9-10), 2619-2631.

107. Walsh, K. J., \& Katzfey, J. J. (2000). The impact of climate change on the poleward movement of tropical cyclone-like vortices in a regional climate model. Journal of Climate, 13(6), 1116-1132. 
108. Walsh, K. J., \& Ryan, B. F. (2000). Tropical cyclone intensity increase near Australia as a result of climate change. Journal of Climate, 13(16), 3029-3036

109. Walsh, K. J., McBride, J. L., Klotzbach, P. J., Balachandran, S., Camargo, S. J., Holland, G., ... \& Sugi, M. (2016). Tropical cyclones and climate change. Wiley Interdisciplinary Reviews: Climate Change, 7(1), 65-89.

110. Walsh, K. J., McInnes, K. L., \& McBride, J. L. (2012). Climate change impacts on tropical cyclones and extreme sea levels in the South Pacific-A regional assessment. Global and Planetary Change, 80, 149-164.

111. Wang, W., \& Seaman, N. L. (1997). A comparison study of convective parameterization schemes in a mesoscale model. Monthly Weather Review, 125(2), 252-278.

112. Wang, Y. (2002). An Explicit Simulation of Tropical Cyclones with a Triply Nested Movable Mesh Primitive Equation Model: TCM3. Part II: Model Refinements and Sensitivity to Cloud Microphysics Parameterization*. Monthly weather review, 130(12), 3022-3036.

113. Weisberg, R. H., \& Zheng, L. (2006). Hurricane storm surge simulations for Tampa Bay. Estuaries and Coasts, 29(6), 899-913.

114. Yang, M. J., \& Ching, L. (2005). A modeling study of Typhoon Toraji (2001): Physical parameterization sensitivity and topographic effect. Terr. Atmos. Oceanic Sci, 16, 177-213.

115. Zhang, C., Wang, Y., \& Hamilton, K. (2011). Improved Representation of Boundary Layer Clouds over the Southeast Pacific in ARW-WRF Using a Modified Tiedtke Cumulus Parameterization Scheme. Monthly Weather Review, 139(11), 3489-3513.

116. Zhu, T., \& Zhang, D. L. (2006). Numerical simulation of Hurricane Bonnie (1998). Part II: Sensitivity to varying cloud microphysical processes. Journal of the atmospheric sciences, 63(1), $109-126$. 


\section{Tables}

Table 1

\begin{tabular}{|c|c|c|c|c|}
\hline $\begin{array}{l}\text { Cumulus } \\
\text { Parameterisation }\end{array}$ & $\begin{array}{l}\text { Microphysics } \\
\text { Scheme }\end{array}$ & $\begin{array}{l}\text { Planetary } \\
\text { Boundary Layer }\end{array}$ & Surface Flux & Sea Surface \\
\hline None (CU0) & None (CU0) & None (CU0) & None & Fixed \\
\hline $\begin{array}{l}\text { Kain Fritsch } \\
\text { (CU1 } \\
\text { Kain and Fritsch 1990; } \\
\text { Kain 1993; Kain 2004) }\end{array}$ & $\begin{array}{l}\text { Kessler } \\
\text { (MP1) } \\
\text { (Kessler 1969) }\end{array}$ & $\begin{array}{l}\text { YSU } \\
\text { (PBL1) } \\
\text { (Hong et al. 2006) }\end{array}$ & $\begin{array}{l}\text { Surface flux } \\
\text { coefficient } \\
\text { (ISFTCFLX) }\end{array}$ & $\begin{array}{l}\text { SST Updating } \\
\text { with ERA-I }\end{array}$ \\
\hline $\begin{array}{l}\text { Betts Miller Janjic (CU2) } \\
\text { (Janjic 1994) }\end{array}$ & $\begin{array}{l}\text { WSM 5-class } \\
\text { (MP4) } \\
\text { (Hong et al. 2004) }\end{array}$ & $\begin{array}{l}\text { MYNN } 2.5 \text { level TKE } \\
\text { closure } \\
\text { (PBL5) } \\
\text { (Janic 2002; } \\
\text { Nakanishi and Niino } \\
\text { 2009) }\end{array}$ & & $\begin{array}{l}\text { 1D Ocean Mixed } \\
\text { Layer } \\
\text { (OML) with ERA- } \\
\text { I }\end{array}$ \\
\hline $\begin{array}{l}\text { Grell Devenyi Ensemble } \\
\text { (CU3) } \\
\text { (Grell and Devenyi } \\
\text { 2002) }\end{array}$ & $\begin{array}{l}\text { Ferrier new eta } \\
\text { (MP5) } \\
\text { (Ferrier 1994; Ferrier } \\
\text { et al. 2002) }\end{array}$ & & & $\begin{array}{l}\text { SST Updating } \\
\text { with ERA-I Lag } \\
\text { Fix }\end{array}$ \\
\hline $\begin{array}{l}\text { Grell 3D Ensemble } \\
\text { (CU5) } \\
\text { (Grell 1993; Grell and } \\
\text { Devenyi 2002) }\end{array}$ & $\begin{array}{l}\text { WSM 6-class } \\
\text { graupel } \\
\text { (MP6) } \\
\text { (Hong and Lim } \\
\text { 2006) }\end{array}$ & & & $\begin{array}{l}\text { SST Updating } \\
\text { with REMSS }\end{array}$ \\
\hline $\begin{array}{l}\text { Tiedtke } \\
\text { (CU6) } \\
\text { (Tiedtke 1989; Zhang } \\
\text { et al. 2011) }\end{array}$ & $\begin{array}{l}\text { Thompson } \\
\text { (MP8) } \\
\text { (Thompson et al. } \\
\text { 2004, 2008). }\end{array}$ & & & \\
\hline
\end{tabular}

Table 1: The schemes that were tested in the physics parameterization ensemble. CU schemes are listed in column 1, MP in column 2, PBL in column 3, the surface flux in column 4. The details and differences of the SST sensitivity simulations are given in the last column. 


\section{Table 2}

\begin{tabular}{|c|c|c|c|c|c|}
\hline Run & Run Name & $\begin{array}{c}\text { Landfall } \\
\text { Pressure } \\
\text { deviation from } \\
929(\mathrm{hPa})\end{array}$ & $\begin{array}{c}\text { Translation Speed } \\
\text { Deviation from } \\
32.93(\mathrm{~km} / \mathrm{h})\end{array}$ & $\begin{array}{c}\text { Landfall } \\
\text { Distance } \\
\text { deviation from } \\
146.11^{\circ} \mathrm{E}, 17.87^{\circ} \mathrm{S} \\
(\mathbf{k m}) \\
\end{array}$ & $\begin{array}{l}\text { Error } \\
\text { Index }\end{array}$ \\
\hline 1 & ERA CUOMPOPBLO & 77 & 11.0 & 93 & 1.20 \\
\hline 2 & ERABOM CUOMPOPBLO & 59 & 4.9 & 87 & 0.88 \\
\hline 3 & ERABOM CU2MP4PBL1 & 28 & 2.6 & 98 & 0.55 \\
\hline 4 & ERABOM CU0MP5PBL1 & 27 & 4.8 & 110 & 0.60 \\
\hline 5 & ERA CU1MP5PBL1 & 29 & 19.9 & 87 & 1.12 \\
\hline 6 & ERABOM CU1MP5PBL1 & 17 & 0.8 & 188 & 0.77 \\
\hline 7 & ERABOM CU3MP5PBL1 & 40 & -0.3 & 74 & 0.59 \\
\hline 8 & ERABOM CU5MP5PBL1 & 34 & 0.6 & 122 & 0.65 \\
\hline 9 & ERABOM CU6MP5PBL1 & 24 & 2.2 & 33 & 0.36 \\
\hline 10 & ERABOM CU6MP5PBL1 vert33 & 29 & 1.2 & 21 & 0.39 \\
\hline 11 & ERABOM CU6MP5PBL1 vert55 & 30 & 8.3 & 9 & 0.57 \\
\hline 12 & ERABOM CU6MP5PBL1 vert56 & 28 & 2.0 & 33 & 0.40 \\
\hline 13 & ERABOM CU6MP4PBL1 & 25 & 4.0 & 9 & 0.38 \\
\hline 14 & ERABOM CU6MP8PBL1 & 34 & 2.7 & 33 & 0.47 \\
\hline 15 & ERABOM CU6MP6PBL1 & 26 & 2.9 & 25 & 0.38 \\
\hline 16 & ERABOM CU6MP6PBL1isflx & 29 & 3.7 & 17 & 0.42 \\
\hline 17 & ERABOM CU6MP6PBL1isflxOML & 26 & 3.2 & 17 & 0.38 \\
\hline 18 & ERABOM CU6MP6PBL5isflxOML & 35 & 3.6 & 58 & 0.54 \\
\hline 19 & ERABOM CU6MP5PBL5isflxOML & 37 & 0.8 & 36 & 0.50 \\
\hline 20 & ERABOM CU6MP5PBL1isflxOML & 35 & 2.9 & 84 & 0.58 \\
\hline 21 & ERABOM CU6MP5PBL1isflx & 30 & 2.6 & 39 & 0.44 \\
\hline 22 & ERABOM CU1MP5PBL1isflxOML & 21 & 1.3 & 168 & 0.71 \\
\hline 23 & ERABOM CU1MP6PBL1isflxOML & 22 & 1.5 & 200 & 0.83 \\
\hline 24 & ERABOM CU1MP6PBL1isflx & 21 & 1.4 & 216 & 0.89 \\
\hline 25 & ERABOM CU1MP6PBL1 & 20 & 1.1 & 216 & 0.88 \\
\hline 26 & ERABOM CU1MP6PBL5isflxOML & 26 & 1.9 & 135 & 0.63 \\
\hline 27 & ERABOM CU2MP1PBL1isflxOML & 38 & 5.2 & 256 & 1.15 \\
\hline 28 & ERABOM CU6MP5PBL1 & 27 & 3.8 & 25 & 0.41 \\
\hline 29 & ERABOM CU6MP5PBL1sstupdate & 28 & 1.6 & 68 & 0.45 \\
\hline 30 & ERABOM CU6MP5PBL1OML & 26 & 2.2 & 67 & 0.44 \\
\hline 31 & ERABOM CU6MP5PBL1LAGFIX & 28 & 2.0 & 33 & 0.40 \\
\hline 32 & ERABOM CU6MP5PBL1REMSS & 22 & 1.7 & 25 & 0.31 \\
\hline 33 & ERABOM CU1MP5PBL1 & 17 & 0.4 & 194 & 0.79 \\
\hline 34 & ERABOM CU1MP5PBL1sstupdate & 17 & 0.7 & 172 & 0.71 \\
\hline 35 & ERABOM CU1MP5PBL1OML & 18 & 0.8 & 183 & 0.75 \\
\hline 36 & ERABOM CU1MP5PBL1LAGFIX & 17 & 0.9 & 188 & 0.77 \\
\hline 37 & ERABOM CU1MP5PBL1REMSS & 16 & 1.0 & 172 & 0.71 \\
\hline
\end{tabular}

Table 2: Details of the initialization, physics parameterization, and SST boundary

condition set up of each ensemble run (column 1). The resulting deviation of the 
simulated landfall pressure (hPa, rounded to the nearest whole number); translation speed $(\mathrm{km} / \mathrm{h}$, rounded to one decimal place); landfall location $(\mathrm{km}$, rounded to nearest whole number) compared to observations; and the error index from the root mean square error calculation (rounded to two decimal places) are provided in columns 2-5. 


\section{List of figures}

Figure 1: The trajectory and category evolution of TC Cyclone Yasi plotted from observations provided by the Australian Bureau of Meteorology (BOM), 2011 from $03 Z$ February $2^{\text {nd }}$ to $12 Z$ February $5^{\text {th }}$ UTC. Yasi intensifies to a category 5 system in the Coral Sea and remains at this category up to the time of landfall.

Figure 2: The 2-domain nested WRF-ARW v3.4.1 set up: d01 has 36km horizontal grid spacing and $\mathrm{d} 02$ has $12 \mathrm{~km}$ resolution.

Figure 3: The sea level pressure (SLP) data in the initial condition data set of a) ERAInterim reanalysis and b) the BOM 4km ACCESS-TC analysis file at January 312011 00UTC. The high resolution BOM data (b) manages to capture the structure and SLP change associated with TC Yasi that is largely missing from the ERA-I file (a).

Figure 4: A comparison of the trajectories from observed data (IBTrACS solid black line), from the ERA-I reanalysis data (solid blue line) to the WRF simulated trajectories when using the ERAI data for lateral and boundary conditions (dashed blue line) or ERAI with ACCESS (BOM) initial conditions with CU1MP5PBL1 physics prescribed (corresponding to Table 2 Runs 5 and 6).

Figure 5: The minimum sea level pressure (SLP, red) and maximum recorded wind speeds (blue) at each time step through the simulations with just ERA-I initialization (solid lines) compared with initializing with ERA-I and the BOM data (dashed lines). The observed SLP evolution is depicted in red with ' $\mathrm{x}$ ' markers. Initializing with the BOM data reduces the SLP and increases the simulated wind speeds when no physics parameterizations are employed (a, corresponding to Table 2, Runs 1 and 2), and when CU1 MP5 PBL1 physics are employed (b, corresponding to Table 2, Runs 5 and 6). 
Figure 6: The SST data on February 2nd, 2011 12h UTC when Yasi is nearing landfall provided by a) the ERA-Interim 6 hourly surface data, b) the ERA-Interim 6 hourly surface data when the 30 hour lag is corrected for, c) the OSTIA SST that the ERA-I reanalysis data uses and d) the $1^{\circ} \times 1^{\circ}$ resolution REMSS MW OI SST daily data set. Yasi's simulated trajectory using each of these SST scenarios and the Tiedtke CU is overlain on each plot with a black line. e) shows the average SST over a $2^{\circ} \times 2^{\circ}$ box centered on $155^{\circ} \mathrm{E}$ and $15^{\circ} \mathrm{S}$ over time for the data from ERA-I reanalysis, OSTIA data, and from ERA-I with 30 hour lag fixed. The line plot shows the 30 hour lag in SSTs between ERA-I and OSTIA data and that when ERA-I values are corrected by 30 hours they match the OSTIA observations. Figure 7: Simulated TC trajectories from each member in the physics sensitivity ensemble, color-coded by the CU parameterization scheme utilized. Observed trajectory is depicted by white circle marker and the landfall location by the large " $\mathrm{X}$ ". The clustering of like colors and thus the effect of the cumulus schemes on the trajectory is apparent.

Figure 8: the simulated temperature and wind speeds at the $700 \mathrm{mb}$ level averaged over the 96 hours of the simulation with the TC trajectory overlain for a) the Kain Fritsch scheme and b) the Tiedtke scheme (corresponding to Table 2, Runs 6 and 9 respectively). c) The difference in the average temperature and wind fields at $700 \mathrm{mb}$ between the two schemes calculated by Kain Fritsch - Tiedtke.

Figure 9: The simulated minimum SLP (red) and the average radius (from the four quadrants of the TC of $64 \mathrm{knot}$ winds (green) simulated at each time step through the simulation with using CU1MP5PBL1 (solid lines, corresponding to Table 2, Run 6) compared to CU6MP5PBL1 (dashed lines, corresponding to Table 2, Run 9) parameterizations. The observed timing and SLP at landfall is marked with red X. The Kain 
Fritsch scheme (CU1, solid line) results in a much lower SLP (greater intensity) and greater radius of 64knot winds (larger TC) than with the Tiedtke scheme (CU6).

Figure 10: Scatterplot of physics sensitivity ensemble members based on their landfall distance anomaly and landfall pressure anomaly compared to observed (marked by the black $\mathrm{X}$ at 0,0$)$. The ensemble runs are represented by color according to the $\mathrm{CU}$ parameterization and symbol shape represents the MP scheme utilized in the simulation. The clustering of like colors and thus cumulus schemes is apparent. Details of each ensemble member set up, landfall distance, timing, and pressure anomaly and the corresponding calculated skill score are given in Table 2.

Figure 11: The sensitivity of the simulations to different representations of the sea surface 1) ERA-I SSTs do not vary temporally 2) updating the SSTs from ERA-I every day, 3) allowing the TC to cool the ocean surface with a 1-D ocean mixed layer model, 4) updating the SSTs from ERA-I but fixing the 30hr lag in ERA-I, and 5) using SSTs from REMSS which have a higher spatial resolution than the SSTs from ERA-I. Sensitivity of the trajectories when employing the Kain Fritsch (a) and Tiedtke (b) schemes. The SST temperature under the eye of the storm at every time step through the simulation for the Kain Fritsch (c) and Tiedtke (d) members. The minimum sea level pressure recorded at every time step through the simulations with Kain Fritsch (e) and Tiedtke (f). The red X denotes the observed SLP at landfall of Yasi. Figures a, c, e correspond with Table 2 Runs 33-37 and figures b, d, f show Table 2 Runs 28-32.

Figure 12: The calculated difference in the simulated relative vorticity fields at the $500 \mathrm{hPa}$ level at time step 50 with REMSS SST - the ERA-I SST when using (a) Kain Fritsch cumulus scheme and (b) Modified Tiedtke scheme. Using the REMSS SST increases relative voriticity with both physics parameterizations, indicating vortex stretching and 
increased intensity. For the Kain Fritsch scheme (a), the change is confined around the eye, while there is a greater change within the eye and over the whole cross section of the system in response to the altered SSTs with the Tiedtke scheme (b). The simulations depicted correspond with Table 2, Runs 29, 32, 34, 37. 


\section{Captioned Figures}

Fig.1

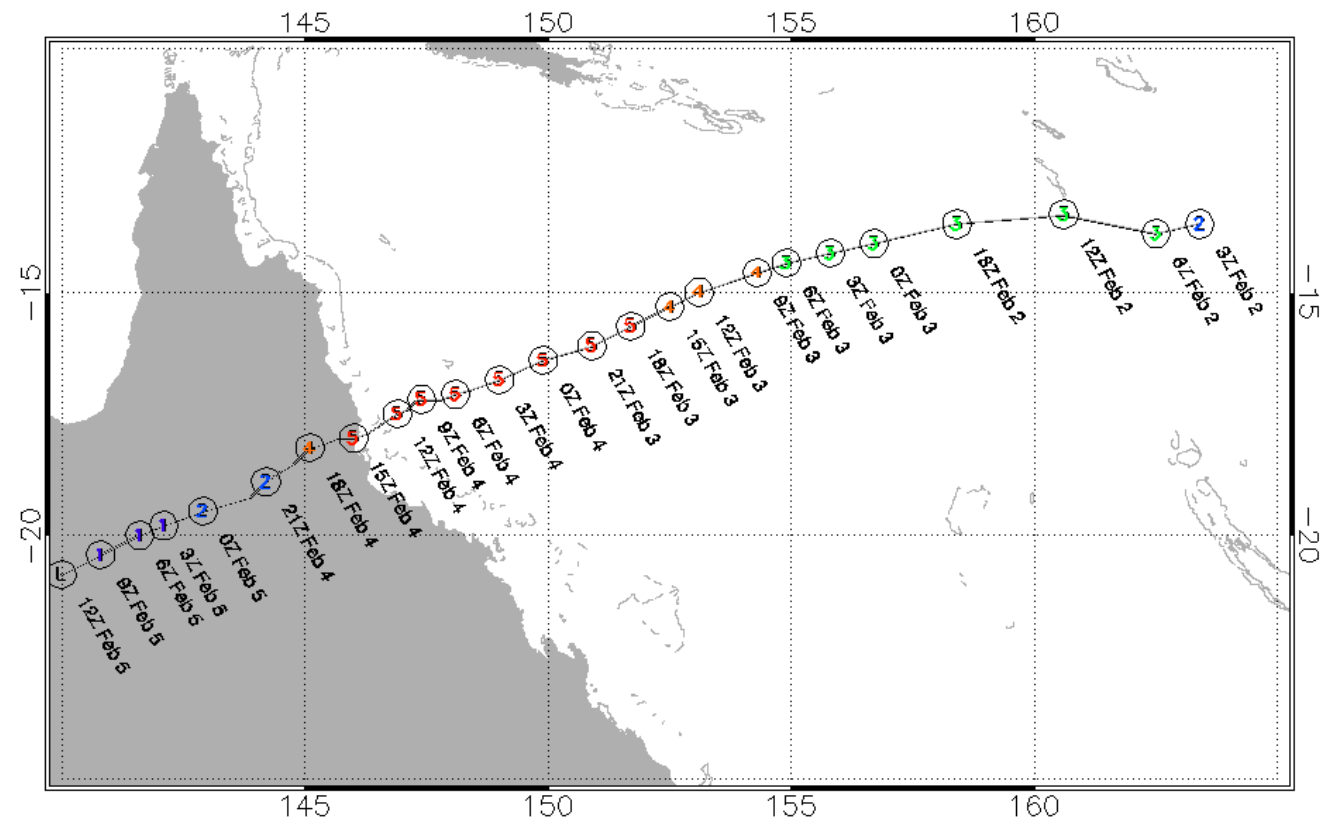

Figure 1: The trajectory and category evolution of TC Cyclone Yasi plotted from observations provided by the Australian Bureau of Meteorology (BOM), 2011 from 03Z February $2^{\text {nd }}$ to $12 Z$ February $5^{\text {th }}$ UTC. Yasi intensifies to a category 5 system in the Coral Sea and remains at this category up to the time of landfall. 
Fig.2

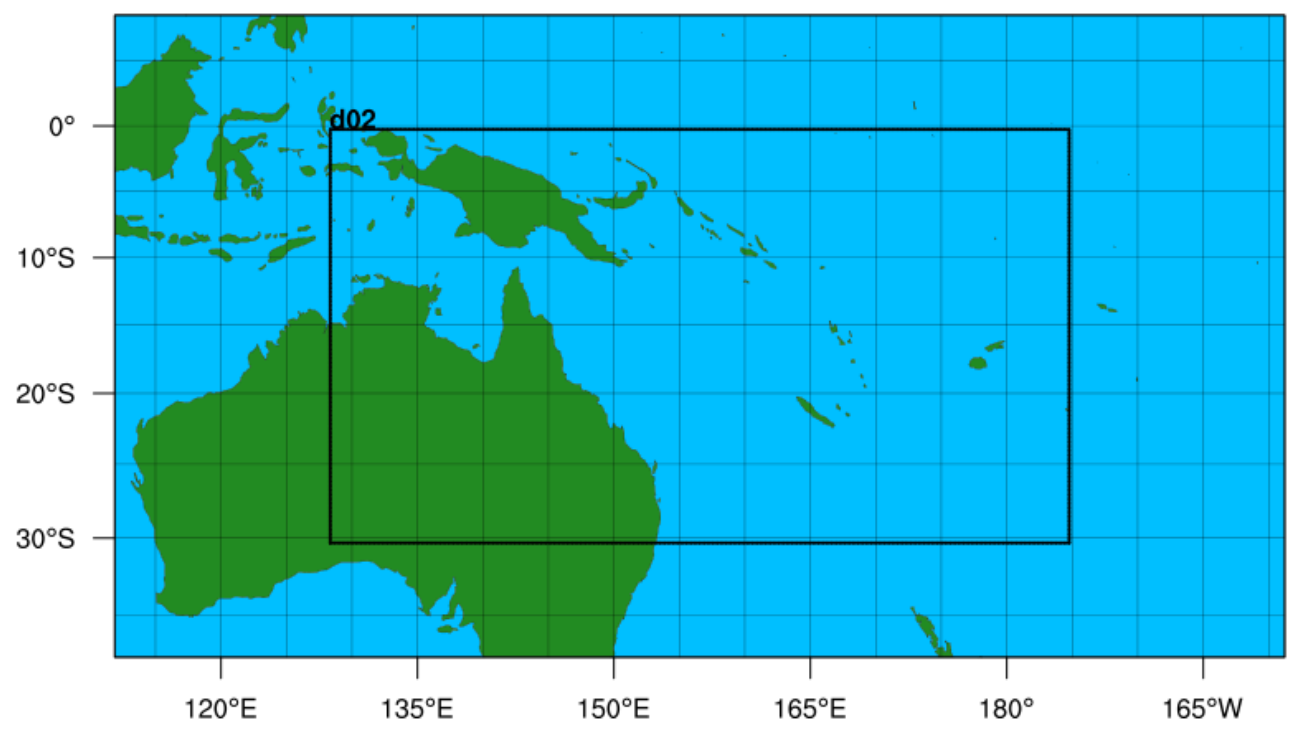

Figure 2: The 2-domain nested WRF-ARW v3.4.1 set up: d01 has 36km horizontal grid spacing and $\mathrm{d} 02$ has $12 \mathrm{~km}$ resolution. 
Fig. 3
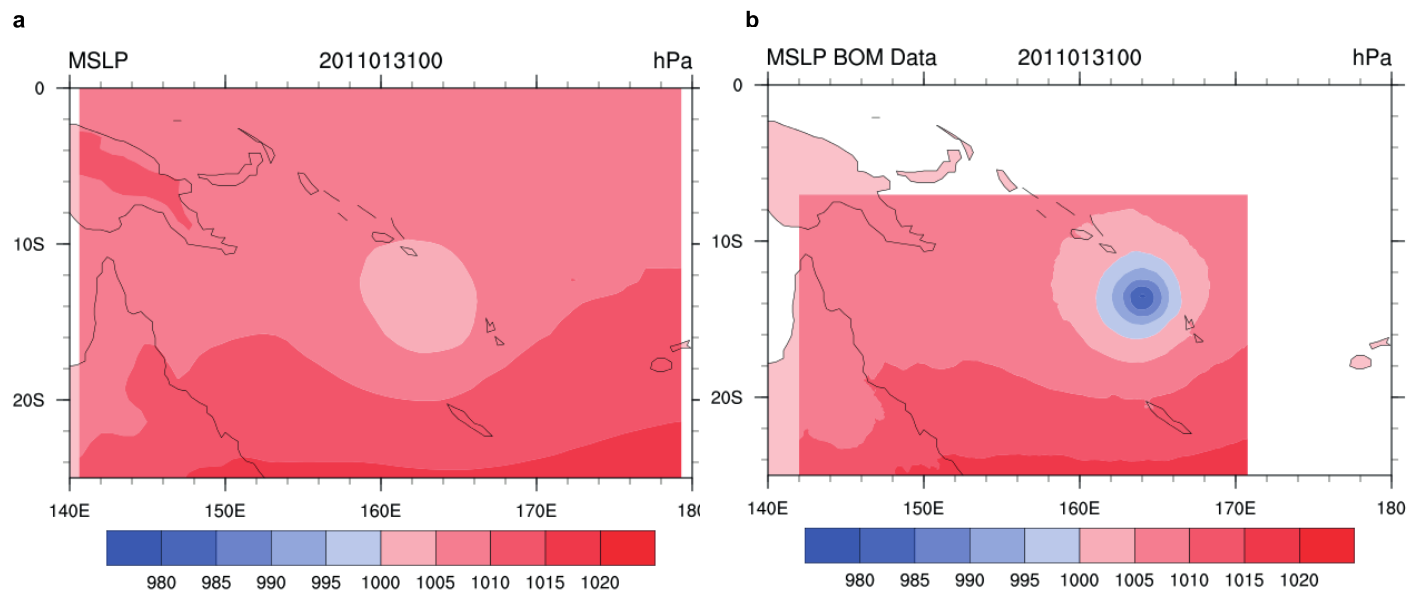

Figure 3: The sea level pressure (SLP) data in the initial condition data set of a) ERAInterim reanalysis and b) the BOM 4km ACCESS-TC analysis file at January 312011 00UTC. The high resolution BOM data (b) manages to capture the structure and SLP change associated with TC Yasi that is largely missing from the ERA-I file (a). 
Fig. 4

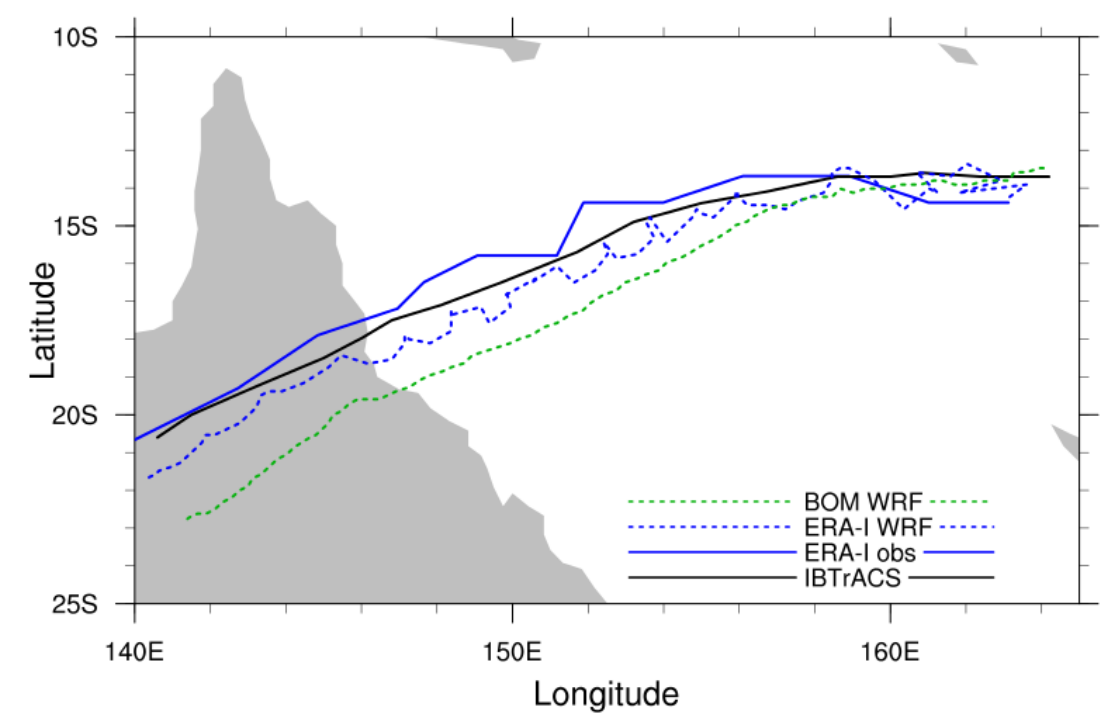

Figure 4: A comparison of the trajectories from observed data (IBTrACS solid black line), from the ERA-I reanalysis data (solid blue line) to the WRF simulated trajectories when using the ERAI data for lateral and boundary conditions (dashed blue line) or ERAI with ACCESS (BOM) initial conditions with CU1MP5PBL1 physics prescribed (corresponding to Table 2 Runs 5 and 6). 
Fig. 5
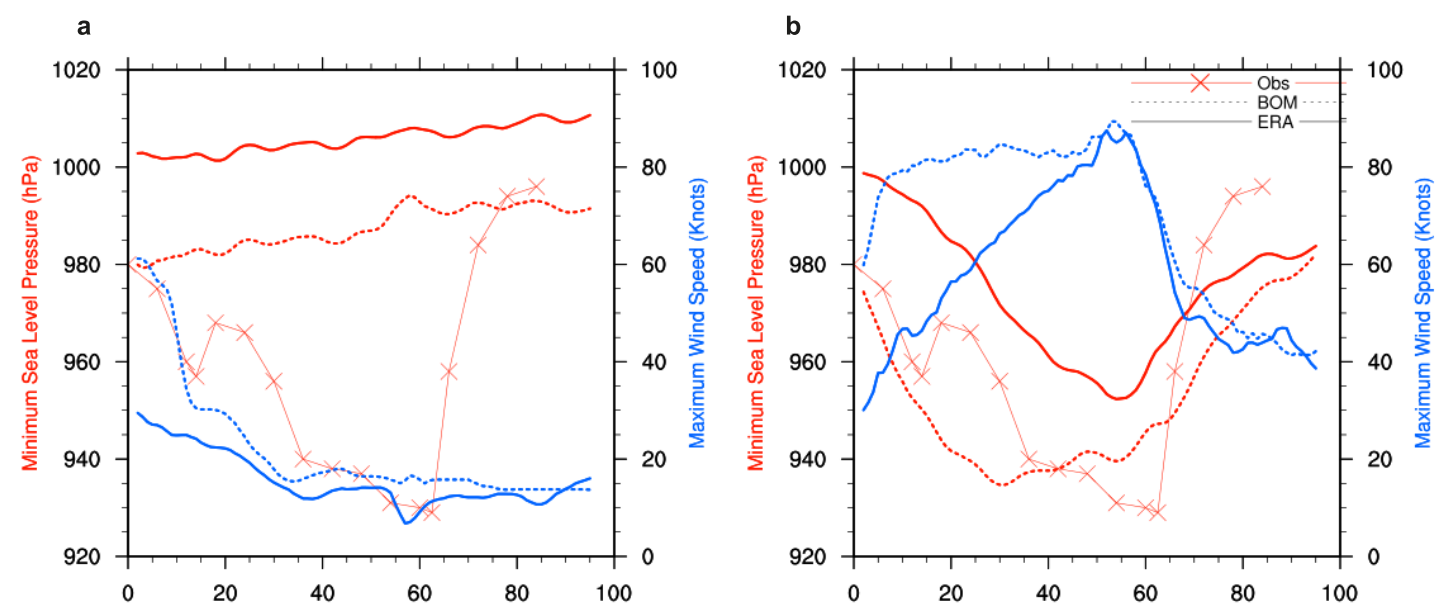

Figure 5: The minimum sea level pressure (SLP, red) and maximum recorded wind speeds (blue) at each time step through the simulations with just ERA-I initialization (solid lines) compared with initializing with ERA-I and the BOM data (dashed lines). The observed SLP evolution is depicted in red with ' $\mathrm{x}$ ' markers. Initializing with the BOM data reduces the SLP and increases the simulated wind speeds when no physics parameterizations are employed (a, corresponding to Table 2, Runs 1 and 2), and when CU1 MP5 PBL1 physics are employed (b, corresponding to Table 2, Runs 5 and 6). 
Fig. 6
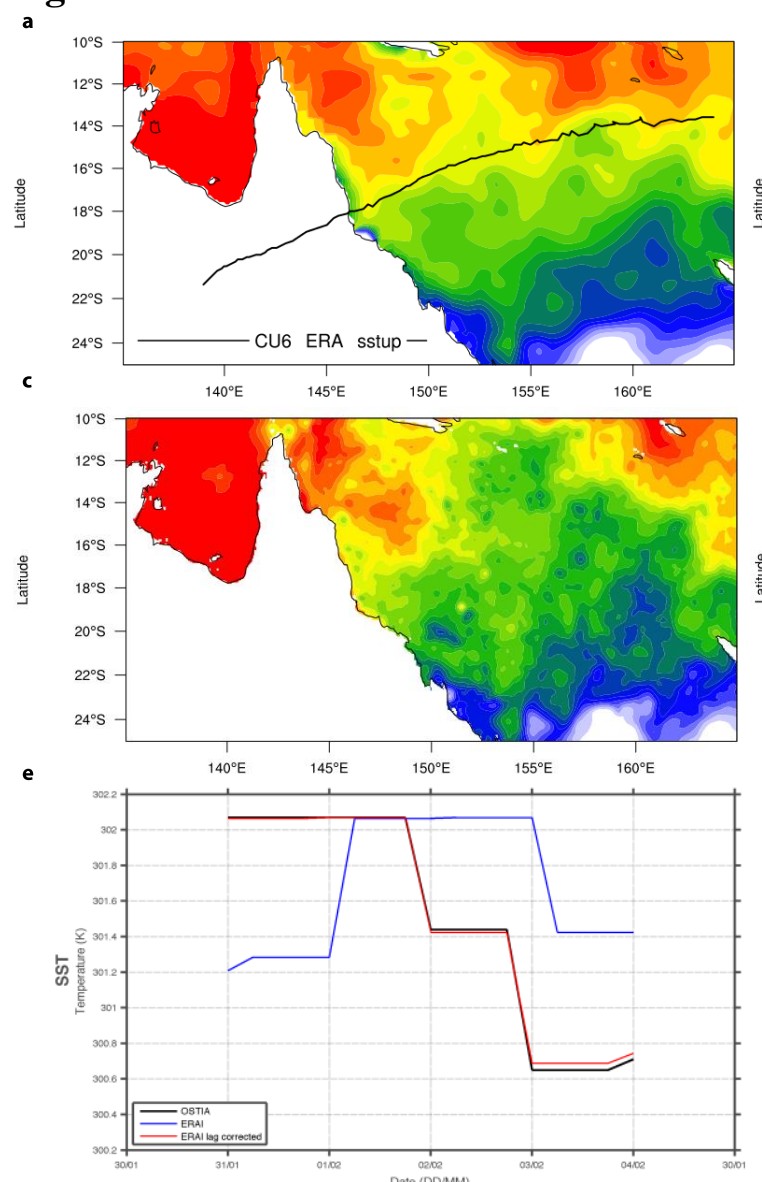
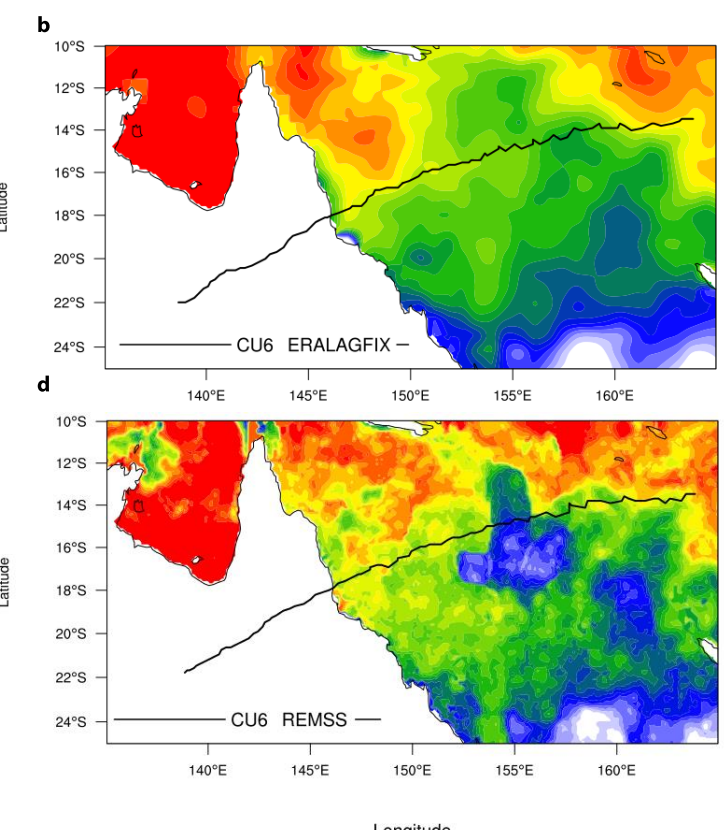

Longitude

SEA SURFACE TEMPERATURE (K) $\begin{array}{lllllll}299.4 & 300 & 300.6 & 301.2 & 301.8 & 302.4 & 303\end{array}$

Figure 6: The SST data on February $2^{\text {nd }}, 2011$ 12h UTC when Yasi is nearing landfall provided by a) the ERA-Interim 6 hourly surface data, b) the ERA-Interim 6 hourly surface data when the 30 hour lag is corrected for, c) the OSTIA SST that the ERA-I reanalysis data uses and $d$ ) the $1^{\circ} \times 1^{\circ}$ resolution REMSS MW OI SST daily data set. Yasi's simulated trajectory using each of these SST scenarios and the Tiedtke CU is overlain on each plot with a black line. e) shows the average SST over a $2^{\circ} \times 2^{\circ}$ box centered on $155^{\circ} \mathrm{E}$ and $15^{\circ} \mathrm{S}$ over time for the data from ERA-I reanalysis, OSTIA data, and from ERA-I with 30 hour lag fixed. The line plot shows the 30 hour lag in SSTs between ERA-I and OSTIA data and that when ERA-I values are corrected by 30 hours they match the OSTIA observations. 
Fig. 7

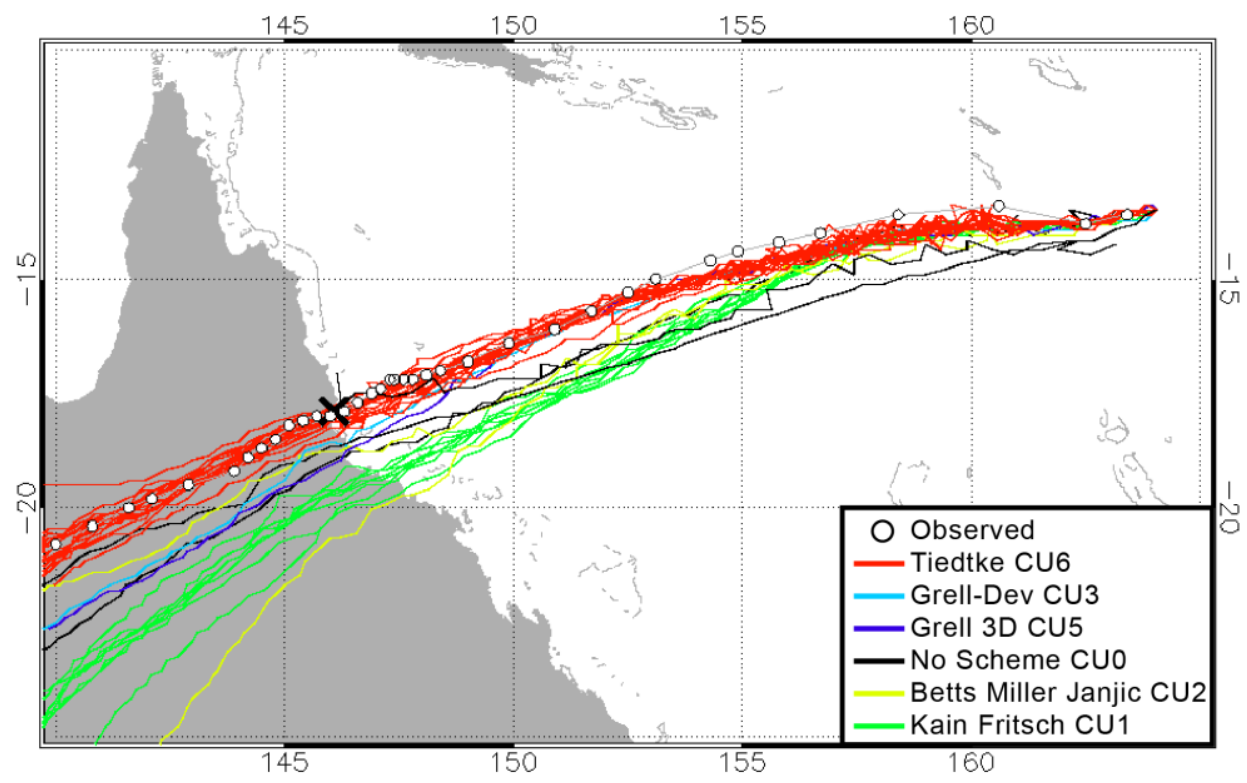

Figure 7: Simulated TC trajectories from each member in the physics sensitivity ensemble, color-coded by the CU parameterization scheme utilized. Observed trajectory is depicted by white circle marker and the landfall location by the large "X". The clustering of like colors and thus the effect of the cumulus schemes on the trajectory is apparent. 
Fig 8.
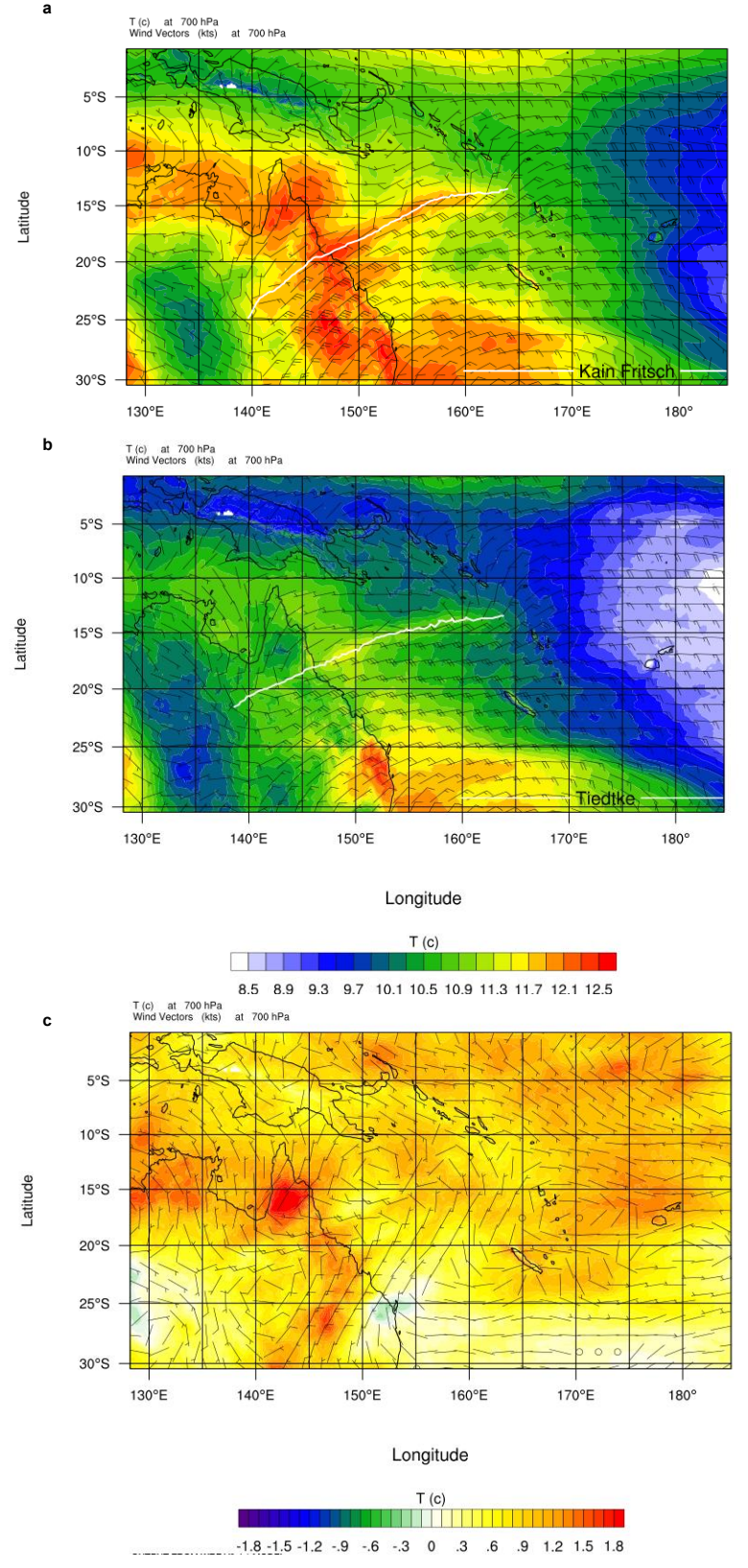

Figure 8: the simulated temperature and wind speeds at the $700 \mathrm{mb}$ level averaged over the 96 hours of the simulation with the TC trajectory overlain for a) the Kain Fritsch scheme and b) the Tiedtke scheme (corresponding to Table 2, Runs 6 and 9 respectively). c) The difference in the average temperature and wind fields at $700 \mathrm{mb}$ between the two schemes calculated by Kain Fritsch - Tiedtke. 
Fig. 9

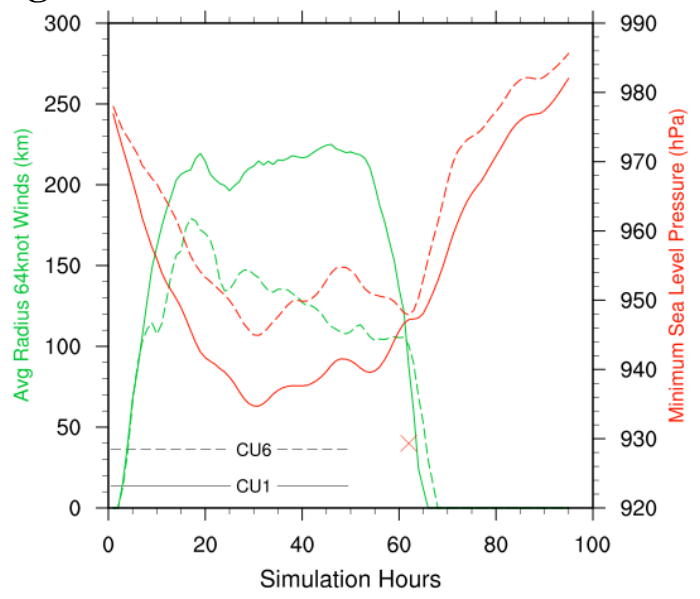

Figure 9: The simulated minimum SLP (red) and the average radius (from the four quadrants of the TC of $64 \mathrm{knot}$ winds (green) simulated at each time step through the simulation with using CU1MP5PBL1 (solid lines, corresponding to Table 2, Run 6) compared to CU6MP5PBL1 (dashed lines, corresponding to Table 2, Run 9) parameterizations. The observed timing and SLP at landfall is marked with red X. The Kain Fritsch scheme (CU1, solid line) results in a much lower SLP (greater intensity) and greater radius of 64knot winds (larger TC) than with the Tiedtke scheme (CU6). 
Fig. 10

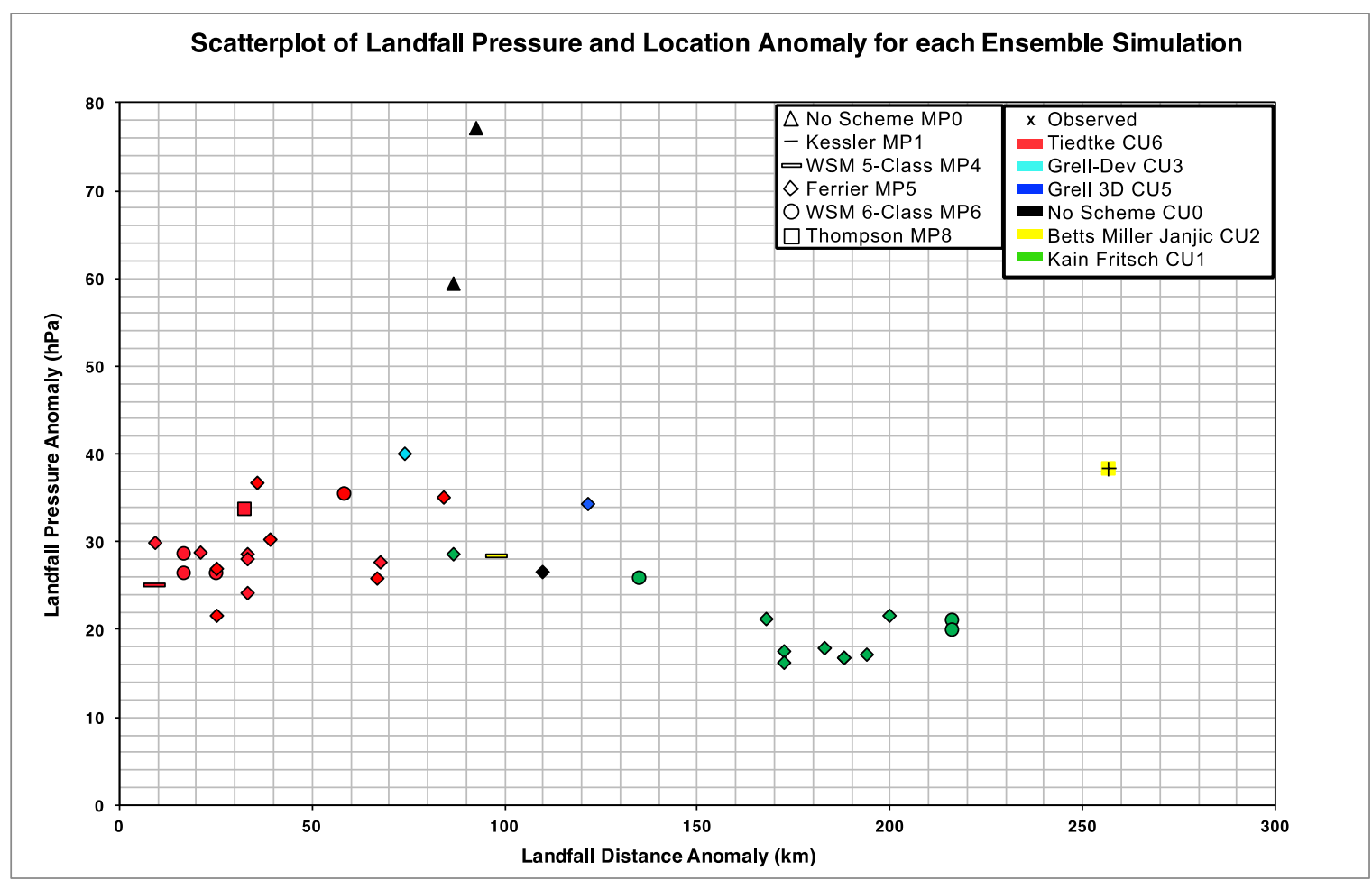

Figure 10: Scatterplot of physics sensitivity ensemble members based on their

landfall distance anomaly and landfall pressure anomaly compared to observed

(marked by the black $\mathrm{X}$ at 0,0 ). The ensemble runs are represented by color

according to the CU parameterization and symbol shape represents the MP scheme

utilized in the simulation. The clustering of like colors and thus cumulus schemes is

apparent. Details of each ensemble member set up, landfall distance, timing, and

pressure anomaly and the corresponding calculated skill score are given in Table 2 . 


\section{Fig 11.}
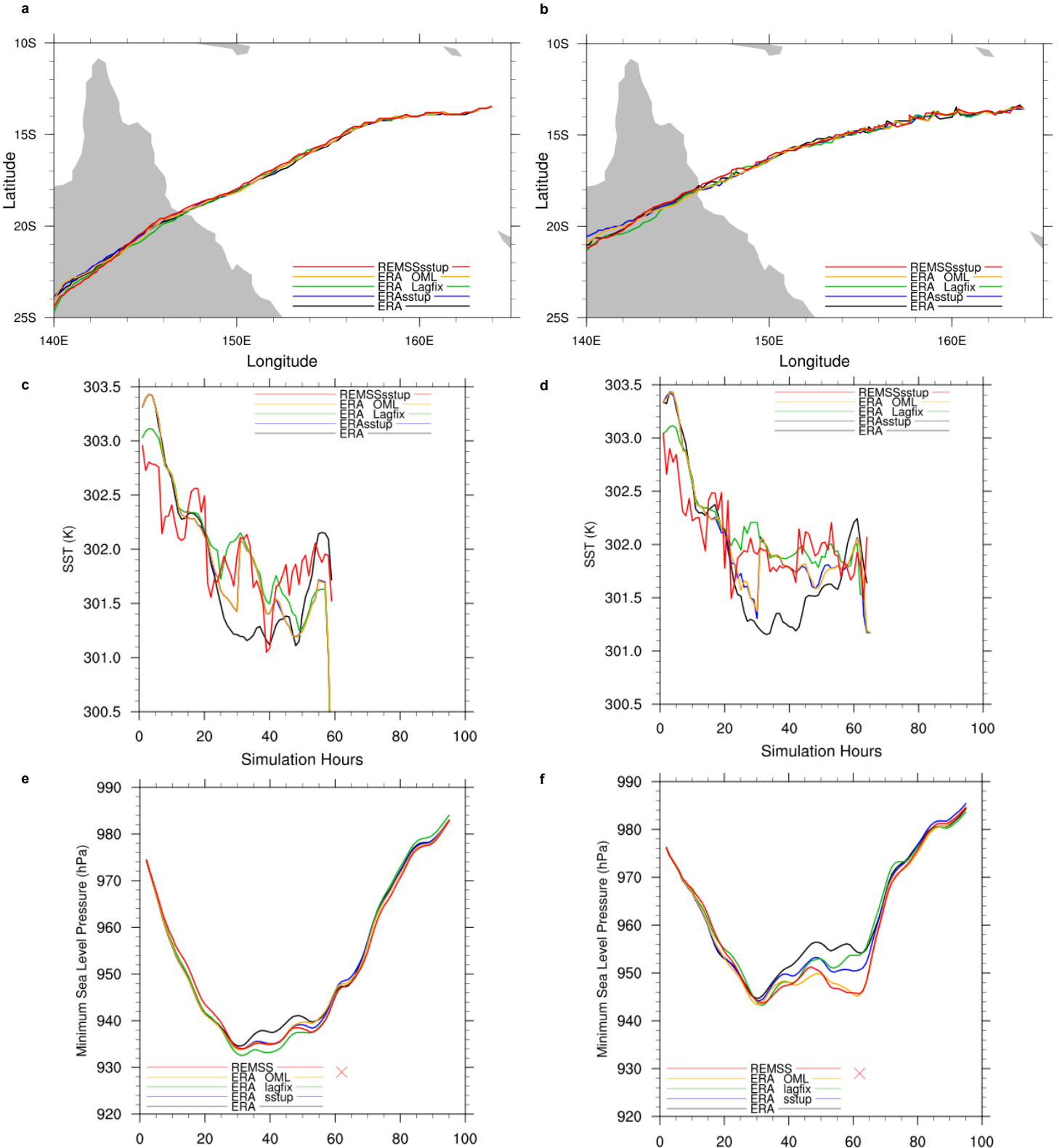

f

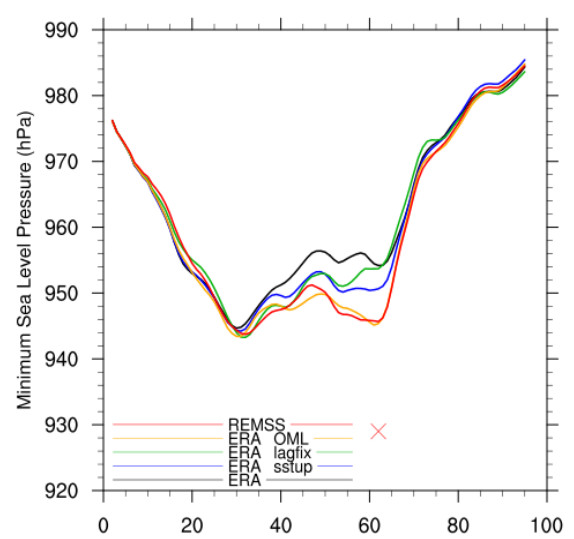

Figure 11: The sensitivity of the simulations to different representations of the sea

surface 1) ERA-I SSTs do not vary temporally 2) updating the SSTs from ERA-I every day, 3) allowing the TC to cool the ocean surface with a 1-D ocean mixed layer model, 4) updating the SSTs from ERA-I but fixing the 30hr lag in ERA-I, and 5) using SSTs from REMSS which have a higher spatial resolution than the SSTs from ERA-I. Sensitivity of the trajectories when employing the Kain Fritsch (a) and Tiedtke (b) schemes. The SST temperature under the eye of the storm at every time step through the simulation for the 
Kain Fritsch (c) and Tiedtke (d) members. The minimum sea level pressure recorded at every time step through the simulations with Kain Fritsch (e) and Tiedtke (f). The red X denotes the observed SLP at landfall of Yasi. Figures a, c, e correspond with Table 2 Runs 33-37 and figures b, d, f show Table 2 Runs 28-32. 
Fig. 12
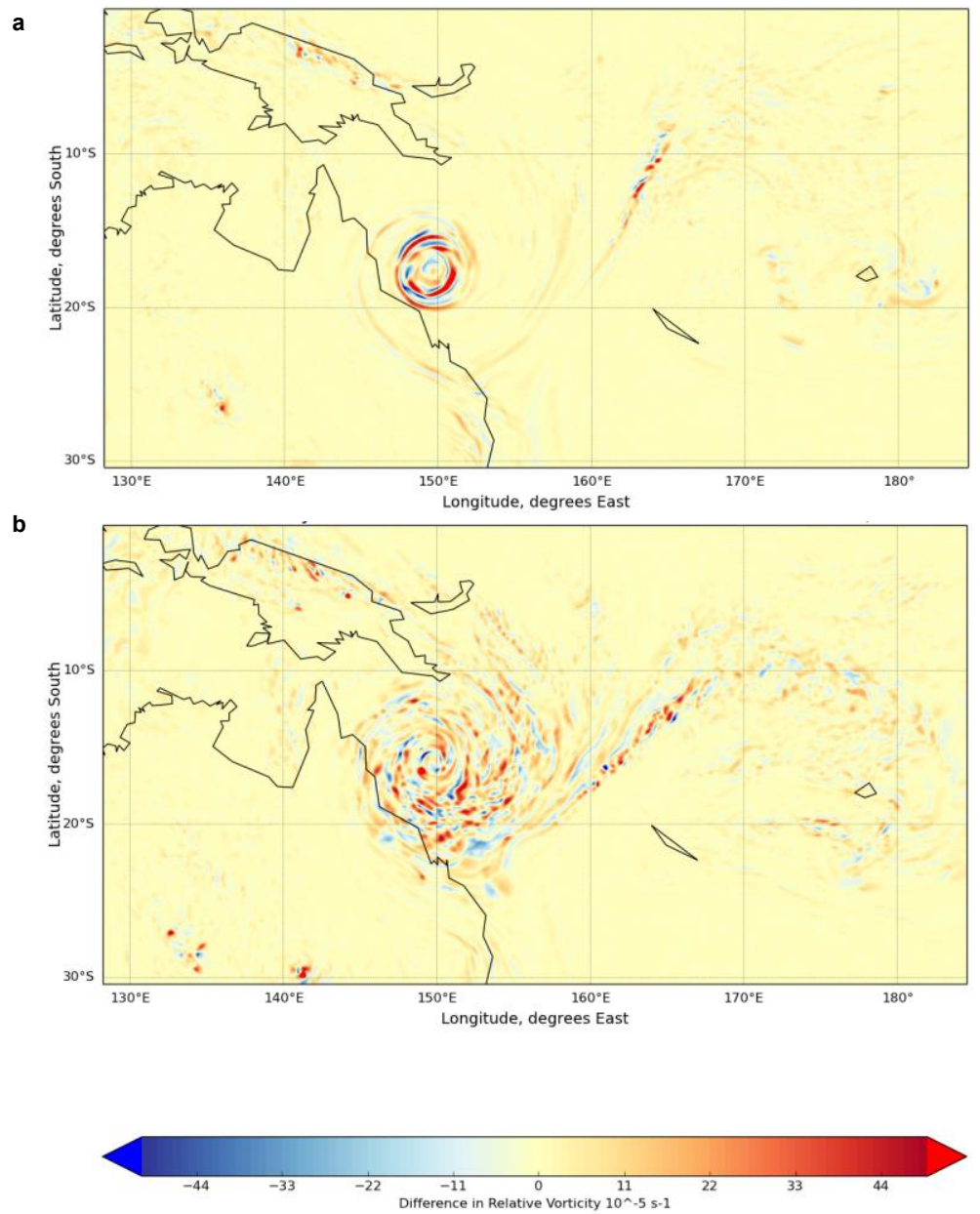

Figure 12: The calculated difference in the simulated relative vorticity fields at the 500hPa level at time step 50 with REMSS SST - the ERA-I SST when using (a) Kain Fritsch cumulus scheme and (b) Modified Tiedtke scheme. Using the REMSS SST increases relative voriticity with both physics parameterizations, indicating vortex stretching and increased intensity. For the Kain Fritsch scheme (a), the change is confined around the eye, while there is a greater change within the eye and over the whole cross section of the system in response to the altered SSTs with the Tiedtke scheme (b). The simulations depicted correspond with Table 2, Runs 29, 32, $34,37$. 
FACTORS AFFECTING THE SIMULATED TRAJECTORY AND INTENSIFICATION OF TROPICAL CYCLONE YASI (2011)

\author{
CHELSEA L. PARKER ${ }^{* 1,2}$, AMANDA H. LYNCH ${ }^{1,2}$, AND PRISCILLA A. \\ MOONEY ${ }^{3}$ \\ ${ }^{I}$ Department of Earth, Environmental and Planetary Sciences, Brown University, \\ Providence, RI, USA. \\ ${ }^{2}$ Institute at Brown for Environment and Society, Brown University, Providence, RI, USA. \\ ${ }^{3}$ National Center for Atmospheric Research, Boulder, CO, USA. \\ Contact: chelsea_parker@brown.edu
}

